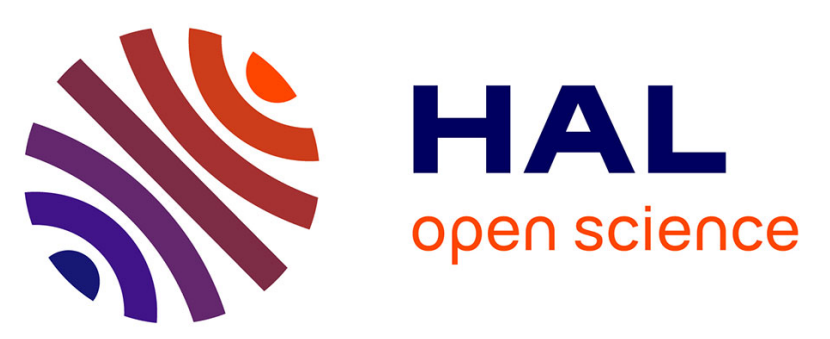

\title{
Zwitterionic Cobalt Complexes with Bis(diphenylphosphino)(N-thioether)amine Assembling Ligands: Structural, EPR, Magnetic, and Computational Studies.
}

Christophe Fliedel, Vitor Rosa, Bertrand Vileno, Nathalie Parizel, Sylvie Choua, Christophe Gourlaouen, Patrick Rosa, Philippe Turek, Pierre Braunstein

\section{- To cite this version:}

Christophe Fliedel, Vitor Rosa, Bertrand Vileno, Nathalie Parizel, Sylvie Choua, et al.. Zwitterionic Cobalt Complexes with Bis(diphenylphosphino)(N-thioether)amine Assembling Ligands: Structural, EPR, Magnetic, and Computational Studies.. Inorganic Chemistry, 2016, 55 (9), pp.4183-4198. 10.1021/acs.inorgchem.5b02889 . hal-01315379

\author{
HAL Id: hal-01315379 \\ https://hal.science/hal-01315379
}

Submitted on 27 Jan 2021

HAL is a multi-disciplinary open access archive for the deposit and dissemination of scientific research documents, whether they are published or not. The documents may come from teaching and research institutions in France or abroad, or from public or private research centers.
L'archive ouverte pluridisciplinaire HAL, est destinée au dépôt et à la diffusion de documents scientifiques de niveau recherche, publiés ou non, émanant des établissements d'enseignement et de recherche français ou étrangers, des laboratoires publics ou privés. 


\section{Zwitterionic Cobalt Complexes with Bis(diphenylphosphino)( $\mathrm{N}$ - thioether)amine Assembling Ligands: Structural, EPR, Magnetic}

and Computational Studies.

Christophe Fliedel, ${ }^{\mathrm{a}}$ Vitor Rosa, ${ }^{\mathrm{a}}$ Bertrand Vileno, ${ }^{\mathrm{b}, \mathrm{c}}$ Nathalie Parizel, ${ }^{\mathrm{b}}$ Sylvie Choua, ${ }^{\mathrm{b}}$ Christophe Gourlaouen, ${ }^{\mathrm{d}}$ Patrick Rosa, ${ }^{\mathrm{e}}$ Philippe Turek ${ }^{\mathrm{b}}$ and Pierre Braunstein ${ }^{\mathrm{a}, *}$

a Laboratoire de Chimie de Coordination, Institut de Chimie (UMR 7177 CNRS), Université de Strasbourg, 4 rue Blaise Pascal, CS 90032, 67081 Strasbourg, France.

E-mail: braunstein@unistra.fr

${ }^{\mathrm{b}}$ Laboratoire POMAM, Institut de Chimie (UMR 7177 CNRS), Université de Strasbourg, 4 rue Blaise Pascal, CS 90032, 67081 Strasbourg, France.

${ }^{\mathrm{c}}$ French EPR Federation of Research (REseau NAtional de Rpe interDisciplinaire (RENARD, Fédération IR-RPE CNRS 3443)

${ }^{\mathrm{d}}$ Laboratoire de Chimie Quantique, Institut de Chimie (UMR 7177 CNRS), Université de Strasbourg, 1 rue Blaise Pascal, 67008 Strasbourg, France.

${ }^{\text {e }}$ CNRS, Université de Bordeaux, ICMCB, UPR9048, F-33600 Pessac, France. 


\begin{abstract}
The coordination of two heterofunctional $P, P, S$ ligands of the $N$-functionalized DPPA-type bearing an alkylthioether or arylthioether $N$-substituent, $\left(\mathrm{Ph}_{2} \mathrm{P}\right)_{2} \mathrm{~N}\left(\mathrm{CH}_{2}\right)_{3} \mathrm{SMe}$ (1) and $\left(\mathrm{Ph}_{2} \mathrm{P}\right)_{2} \mathrm{~N}\left(p-\mathrm{C}_{6} \mathrm{H}_{4}\right) \mathrm{SMe}(2)$, respectively, toward cobalt dichloride was investigated to examine the influence of the linker between the PNP nitrogen and the $S$ atoms. The complexes $\left[\mathrm{CoCl}_{2}(\mathbf{1})\right]_{2}(\mathbf{3})$ and $\left[\mathrm{CoCl}_{2}(\mathbf{2})\right]_{2}(\mathbf{4})$ have been isolated and $\mathbf{3}$ was shown by X-ray diffraction to be a unique dinuclear, zwitterion containing one $\mathrm{CoCl}$ moiety bis-chelated by two ligands $\mathbf{1}$ and one $\mathrm{CoCl}_{3}$ fragment coordinated by the $\mathrm{S}$ atom of a thioether function. The FTIR, UV-vis, and EPR spectroscopic features of $\mathbf{3}$ were analyzed as the superposition of those of constitutive fragments identified by a retrosynthetic-type analysis. A similar approach provided insight into the nature of $\mathbf{4}$ for which no X-ray diffraction data could be obtained. A comparison between the spectroscopic features of $\mathbf{4}$ and of its constitutive fragments, $\left[\mathrm{CoCl}(\mathbf{2})_{2}\right] \mathrm{PF}_{6}(\mathbf{7})$ and $\left[\mathrm{H}^{\prime}\right]_{2}\left[\mathrm{CoCl}_{4}\right](\mathbf{8})\left(\mathbf{2}^{\prime}=\mathrm{NH}_{2}\left(p-\mathrm{C}_{6} \mathrm{H}_{4}\right) \mathrm{SMe}\right)$, and between those of 4 and $\mathbf{3}$, suggested that $\mathbf{4}$ could either have a zwitterionic structure, similar to that of $\mathbf{3}$, or contain a tetrahedral dicationic bis-chelated Co center associated to a $\mathrm{CoCl}_{4}$ dianion. Magnetic and EPR studies and theoretical calculations were performed. Doublet spin states were found for the pentacoordinated complexes $\left[\mathrm{CoCl}(\mathbf{1})_{2}\right] \mathrm{PF}_{6}(\mathbf{5})$ and 7 and anisotropic quadruplet spin states for the tetrahedral complexes $\left[\mathrm{CoCl}_{3}\left(\mathrm{H1} \mathbf{1}^{\prime}\right)\right](\mathbf{6})\left(\mathbf{1}^{\prime}=\mathrm{NH}_{2}\left(\mathrm{CH}_{2}\right)_{3} \mathrm{SMe}\right)$ and $\mathbf{8}$. A very similar behavior was observed for $\mathbf{3}$ and $\mathbf{4}$, consisting in the juxtaposition of non-interacting doublet and quadruplet spin states. Antiferromagnetic interactions explain the formation of dimers for 6 and of layers for $\mathbf{8}$. The EPR signatures of $\mathbf{3}$ and $\mathbf{4}$ correspond to the superposition of lowspin 5 and 7, and high-spin 6 and $\mathbf{8}$ nuclei, respectively. From DFT calculations, the solidstate structure of $\mathbf{4}$ appears best described as zwitterionic, with a low spin state for the Co1 atom.
\end{abstract}




\section{Introduction}

The profuse chemistry of short-bite ligands, particularly the diphosphines bis(diphenylphosphino)methane (DPPM) and bis(diphenylphosphino)amine (DPPA) and their derivatives, magnified by the diversity of their coordination modes (monodentate, bridging, chelating), instigated a longstanding interest across the scientific community. ${ }^{1}$ The versatility of DPPA-type ligands can be amplified by the introduction of various $N$-substituents and empowers an extensive number of applications, such as the formation of mono- or polynuclear complexes, ${ }^{2}$ or the anchoring of coordination compounds into mesoporous materials ${ }^{3}$ or on metallic surfaces. ${ }^{4}$ Metal complexes with such short-bite ligands are involved in various catalytic reactions, ${ }^{5}$ and their $\mathrm{Ni}$ and $\mathrm{Cr}$ derivatives have been successfully applied to the catalytic oligo- or polymerization of ethylene. ${ }^{6,7}$

The study of the electronic structure of first-row transition metal ions in relation with their stereochemistry is a very relevant field in coordination and biological chemistry and it is essential to analyze how stereochemistry, electronic structure and magnetic properties correlate. ${ }^{8,9}$ We became interested in the coordination chemistry of $N$-thioether-functionalized DPPA-type ligands, such as $\left(\mathrm{Ph}_{2} \mathrm{P}\right)_{2} \mathrm{~N}\left(\mathrm{CH}_{2}\right)_{3} \mathrm{SMe}(\mathbf{1})$ and $\left(\mathrm{Ph}_{2} \mathrm{P}\right)_{2} \mathrm{~N}\left(p-\mathrm{C}_{6} \mathrm{H}_{4}\right) \mathrm{SMe}(2)$, with an alkyl or an aryl-spacer, respectively (Chart 1, top), because of ( $i$ ) the versatility of the thioether function, that can act as an intra- or inter-molecular donor toward a metal center or be used to deposit/anchor complexes on metal surfaces, and (ii) the possibility to evaluate the differences of reactivity induced by a change of the linker that connects the PNP moiety and the thioether donor group, for example when going from a flexible propyl to a rigid phenyl. Previous studies have shown i.a. that (i) bis-chelated dicationic Pd(II) complexes with ligands 1 and 2 could be used to assess molecular anchoring on $\mathrm{Au}(111)$ surfaces (Janus microspheres), ${ }^{4}$ (ii) the $\mathrm{N}$-functionalization influences the behavior of $\mathrm{Ni}(\mathrm{II})$ complexes containing such tritopic $P, P, S$ ligands in catalytic ethylene oligomerization, ${ }^{6 \mathrm{a}}$ and (iii) that a combination of dicationic $\mathrm{Ni}(\mathrm{II})$ complexes containing two chelating ligands $\mathbf{1}$ or $\mathbf{2}$, and $\mathrm{Zn}$ metal allows the activation of both $\mathrm{C}_{\mathrm{sp} 3}-\mathrm{Cl}$ bonds of $\mathrm{CH}_{2} \mathrm{Cl}_{2}$ under mild conditions and affords mixed phosphine, phosphonium ylide species. ${ }^{10}$

Further indications that subtle changes in ligand design can strongly affect the nature of the resulting coordination complexes were also provided by the reactions between $\mathrm{FeCl}_{2}$ and ligand 1 or $\mathbf{2}$ (1:1 molar ratio) since they led, under strictly similar reaction conditions, to an infinite coordination polymer or a dinuclear complex, respectively. ${ }^{11}$ It was concluded that electronic factors accounted for the unusual unsymmetrical chelation of the iron center (Chart 
1 , bottom), raising the question of a possible lability of phosphorus donors in solution, which is relevant to catalyst behavior. Whereas studies on the coordination chemistry of DPPA-type ligands have mostly focused on metals of groups 6,10 and $11, \mathrm{Ru}$ and $\mathrm{Rh},{ }^{5,12}$ those on Fe and Co remain scarce, although these earth abundant metals are of considerable current interest and display versatile coordination spheres (coordination numbers and geometries) associated with diverse chemical and physical properties. ${ }^{13}$ One should of course remember that the structures of the metal complexes in solution and in the solid state may not be identical, which justifies the use of various complementary methods for their investigation.<smiles>CSCCCN(P)Pc1ccccc1</smiles>

1<smiles>[R]n1[p-][pH][pH][pH]1</smiles><smiles>CSc1ccc(N(P)Pc2ccccc2)cc1</smiles><smiles></smiles>

Symmetrical vs. unsymmetrical coordination of the DPPA-type ligand

\section{Chart 1.}

Following these observations and recent findings on the magnetic properties of polynuclear Co(II) complexes, ${ }^{14}$ we investigated the coordination chemistry of ligands $\mathbf{1}$ and 2 in cobalt complexes, a metal not much represented in the DPPA-type chemistry landscape. Unexpectedly, dinuclear structures were obtained, as established by X-ray diffraction in the case of the zwitterionic complex $\left[\mathrm{CoCl}_{2}(\mathbf{1})\right]_{2}(\mathbf{3})$ which contains one $\mathrm{CoCl}$ moiety bis-chelated by two ligands 1 and one $\mathrm{CoCl}_{3}$ fragment coordinated by the $\mathrm{S}$ atom of a thioether function. In the absence of X-ray diffraction data for $\left[\mathrm{CoCl}_{2}(2)\right]_{2}(4)$ and in order to better understand its occurrence and properties, we compared its spectroscopic features with those of potential constitutive building blocks. This approach was first validated by performing a similar analysis with 3. The comparisons were based on FT-IR, UV-Vis and EPR spectroscopic data, magnetic measurements and theoretical calculations. 


\section{Results and Discussion}

\section{Synthesis of the Co(II) Complexes and Solid-State Molecular Structures.}

To evaluate the influence of the linker that connects the $S$-donor and the PNP nitrogen atom of ligands 1 and 2 on the nature of their cobalt(II) complexes, these ligands were initially reacted with an equimolar amount of anhydrous $\mathrm{CoCl}_{2}$ in dichloromethane. In both cases, dark green solutions were obtained and the same work-up was applied. After filtration of the reaction mixture, evaporation to dryness of the filtrate and washing of the residue, a green solid was isolated. Crystallization from a dichloromethane/pentane mixture led to dichroïc green/red crystals of complex 3 (ligand 1) and green polycrystalline $\left[\mathrm{CoCl}_{2}(2)\right]_{2}$ (4) (ligand 2) in $55 \%$ and $83 \%$ yields, respectively (Scheme 1 ).

Whereas ${ }^{31} \mathrm{P}$ NMR spectroscopy is commonly used to assess the coordination behavior of $N$-functionalized DPPA-type ligands, ${ }^{1}$ this was not possible here owing to the paramagnetic nature of the $\mathrm{Co}(\mathrm{II})$ center. The precise determination of the coordination sphere around the metal center thus required X-ray diffraction studies on single crystals, complemented by physical and theoretical investigations (see below). While the molecular structure of complex 3 in $3 \cdot 2 \mathrm{CH}_{2} \mathrm{Cl}_{2}$ was unambiguously established by $\mathrm{X}$-ray diffraction studies (Figure 1), no suitable single crystals could be obtained for complex 4, despite many attempts.

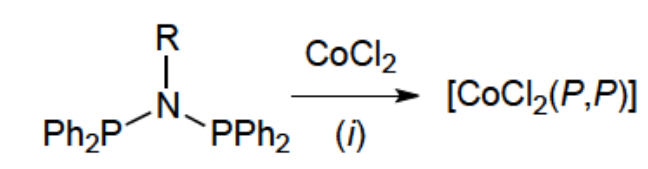

1: $\mathrm{R}=n-\mathrm{PrSMe}$

2: $\mathrm{R}=p-(\mathrm{SMe}) \mathrm{C}_{6} \mathrm{H}_{4}$ dark green solutions

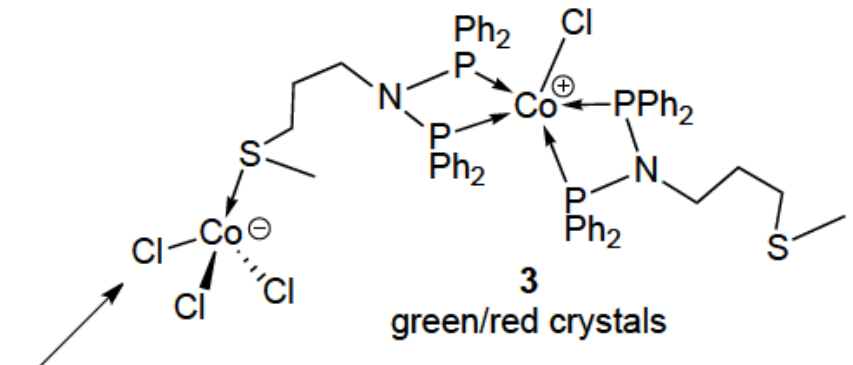

(ii) 
ligand/metal molar ratio used in the synthesis is retained in the structure of the complex, as confirmed by the elemental analysis on ground and dried crystals (see Experimental Section). To the best of our knowledge, there are only 3 examples of structurally characterized cobalt complexes containing one or two $N$-substituted DPPA-type ligands, and none of them exhibits the observed $\left[\mathrm{CoCl}(P, P)_{2}\right]$ or the anticipated $\left[\mathrm{CoCl}_{2}(P, P)\right]$ motif (Figure S25 in ESI). ${ }^{15}$ Panda et al. reported the formation of a mixed-valent dinuclear complex, $\left[\mathrm{Co}^{\mathrm{II}} \mathrm{Cl}_{2}(P, P)_{2}\right] /\left[\mathrm{Co}^{\mathrm{III}} \mathrm{Cl}_{3}\left(\mathrm{NH}_{2}-\mathrm{R}\right)\right]$, resulting from the reaction of a $N$-aryl DPPA-type ligand with $\mathrm{CoCl}_{2} .{ }^{15 \mathrm{a}}$ The $\left[\mathrm{CoCl}_{3}\left(\mathrm{RSR}^{\prime}\right)\right]$ motif is also rare, with only three structures available in the CSD database, ${ }^{16}$ two of them are $\mathrm{Co}^{\mathrm{II}}\left(\mu_{2}-\mathrm{Cl}\right)$ dinuclear complexes and one contains a $\mathrm{Co}^{\mathrm{III}}$ center (Figure S26 in ESI). The two chemically different Co centers in $\mathbf{3}$ exhibit different coordination geometries and are formally part of a cationic (Co1) and an anionic fragment (Co2). The pentacoordination around Co1 corresponds to a slightly distorted trigonal bipyramidal geometry, with P1, P3 and C11 being coplanar and the apical positions being occupied by P2 and P4. The longest basal P-Co bond is P1-Co1 [2.283(2) $\AA$ ] whereas the Co1-P3 [2.221(2) $\AA]$ and $\mathrm{Co1}-\mathrm{Cl}[2.232(2) \AA]$ bond lengths are similar, likewise those between the metal center and the apical ligands [Co1-P2 2.248(2) $\AA$ and Co1-P4 2.233(2) $\AA$ )]. The distortion away from a regular trigonal bipyramidal geometry, as quantified by a continuous symmetry measure $\mathrm{S}\left(D_{3 \mathrm{~h}}\right)=2.11$ (see Table S10 in ESI), ${ }^{17}$ is induced by the PNP chelate, with P1-Co1-P2 and P3-Co1-P4 angles of 71.69(6) ${ }^{\circ}$ and $71.33(7)^{\circ}$, respectively. The second Co center $(\mathrm{Co} 2)$ is in a distorted tetrahedral coordination environment containing three similarly spaced $\mathrm{Cl}$ ligands [Co-Cl bond lengths in the range 2.236(2)-2.246(2) $\AA$ ], whereas the Co2-S2 bond of 2.396(2) $\AA$ is significantly longer, consistent with the larger covalent radius of $\mathrm{S} v s$. $\mathrm{Cl}$. The angles involving $\mathrm{S} 2$ span a broader range [between $\mathrm{Cl}$-Co2-S2 97.74(7) and C14-Co2-S2 $108.49(8)^{\circ}$ ] than those involving only chlorides and the cobalt center [between Cl4-Co2-Cl2 112.79(9) and Cl3-Co2-C12 117.92(8) ${ }^{\circ}$. 


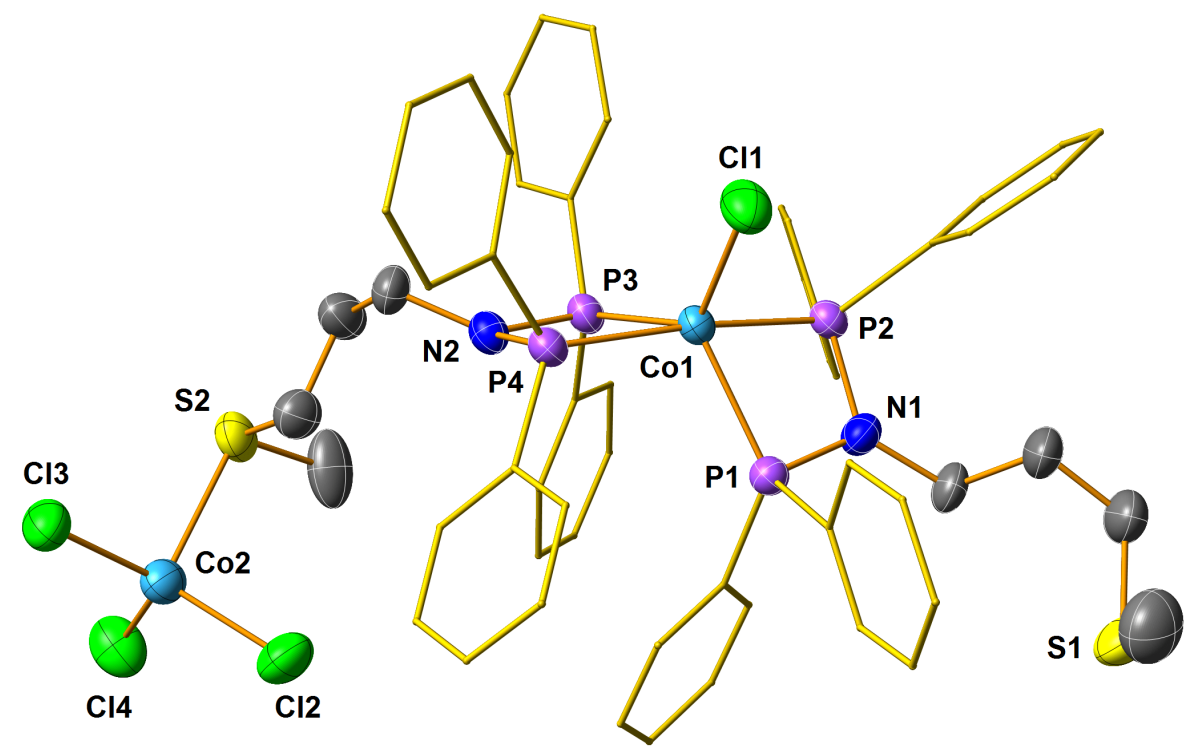

Figure 1. View of the molecular structure of the zwitterionic complex 3 in $3 \cdot 2 \mathrm{CH}_{2} \mathrm{Cl}_{2}$. Solvent molecules and hydrogen atoms were omitted for clarity. Ellipsoids are represented at $50 \%$ probability level. Selected bond lengths and angles are reported in Table 1.

The structure of complex 4 could not be determined by single crystal X-ray diffraction analysis, but elemental analysis performed on a microcrystalline powder was in agreement with the 1:1 ligand/metal ratio used, as in 3 (see Experimental Section). Interestingly, in the ESI-MS spectra ( $\mathrm{MeCN} / \mathrm{CH}_{2} \mathrm{Cl}_{2}$ solutions) of 3 and $\mathbf{4}$, both the $\left[M-\mathrm{H}-\mathrm{CoCl}_{4}\right]^{+}(\mathrm{m} / z$ 1005.1 (3) and $1073.1(4))$ and $\left[M-\mathrm{CoCl}_{3}\right]^{+}$fragments $(\mathrm{m} / \mathrm{z} 1040.1(3)$ and $1108.1(4))$, were detected as major peaks, however with a 4:1 and 2:1 ratio in intensity, respectively.

We expected to gain more information about the nature of $\mathbf{4}$ from a comparison of its far infra-red (far-FT-IR) spectrum in the region corresponding to the $v(\mathrm{Co}-\mathrm{Cl})$ vibrations (600-100 $\mathrm{cm}^{-1}$ ), with that of complex 3 . However, the spectra recorded were not conclusive (see below).

At this stage, two hypotheses concerning the structure of complex $\mathbf{4}$ could be reasonably envisaged: $(i)$ a structure similar to that of complex $\mathbf{3}$, with a $\mathrm{CoCl}$ moiety bischelated by two ligands 2 and a $\mathrm{CoCl}_{3}$ fragment coordinated by a thioether donor, ${ }^{2 \mathrm{a}}$ (Chart 2 , left) or (ii) an ion-pair with a tetrahedral dicationic bis-chelated Co center associated with a $\mathrm{CoCl}_{4}$ dianion (Chart 2, right). The latter situation, i.e. the formation of a $\mathrm{ML}_{2} / \mathrm{MCl}_{4}(\mathrm{~L}=$ chelating ligand) formula isomer of a $\mathrm{MCl}_{2} \mathrm{~L}$ complex, has been recently observed in a $\mathrm{Ni}(\mathrm{II})$ complex supported by the mono-sulfido ligand $\mathbf{1} \cdot \mathrm{S}$, in which a dicationic Ni(II) center was bis-chelated by two $(P, \mathrm{P}=S)$ ligands, while a $\mathrm{NiCl}_{4}$ dianion balanced the charge. ${ }^{18}$ 

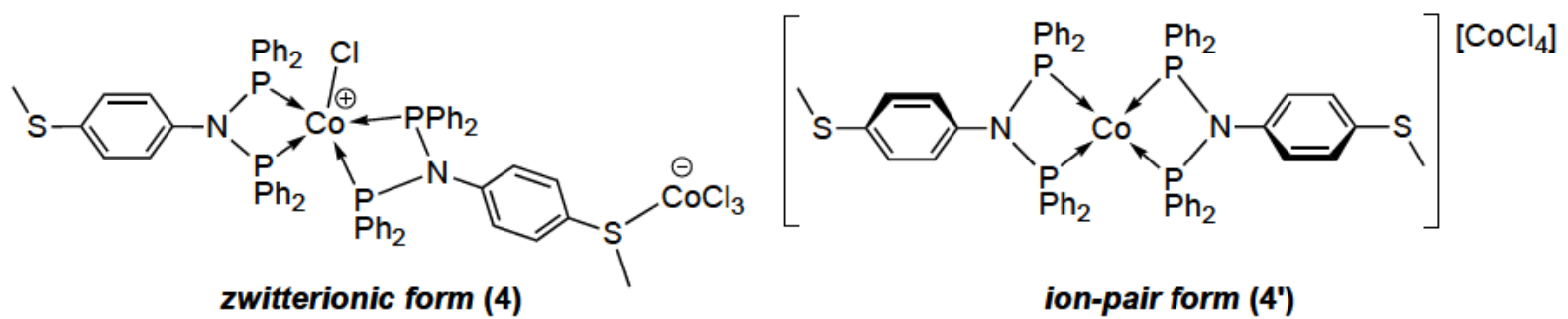

ion-pair form (4')

Chart 2. Proposed zwitterionic (4, left) and ion-pair (4', right) forms for complex $\left[\mathrm{CoCl}_{2}(\mathbf{2})\right]_{2}$.

Since the molecular structure of $\mathbf{4}$ was not directly accessible by X-ray crystallography or indirectly by comparison of its spectroscopic data (FT-IR, UV-vis, EPR see below) with those of zwitterion 3, we targeted the formation of mononuclear complexes/fragments potential building blocks of $\mathbf{4}$ to access their spectroscopic fingerprints, compare them with those of $\mathbf{4}$ and see whether the latter could be analyzed as being the "simple" superposition of those of the constitutive fragments.

First applied to the structurally characterized complex $\mathbf{3}$ for validation, this strategy led us to synthesize the complex $\left[\mathrm{CoCl}(\mathbf{1})_{2}\right] \mathrm{PF}_{6}(\mathbf{5})$, containing the anticipated cationic $(P, P)$ bis-chelated $\mathrm{CoCl}$ unit, and the zwitterionic complex $\left[\mathrm{CoCl}_{3}\left(\mathrm{H1} \mathbf{1}^{\prime}\right)\right](\mathbf{6})\left(\mathbf{1}^{\prime}=\mathrm{NH}_{2}\left(\mathrm{CH}_{2}\right)_{3} \mathrm{SMe}\right)$, which displays the anionic $\mathrm{S}-\mathrm{CoCl}_{3}$ moiety (Scheme 2).

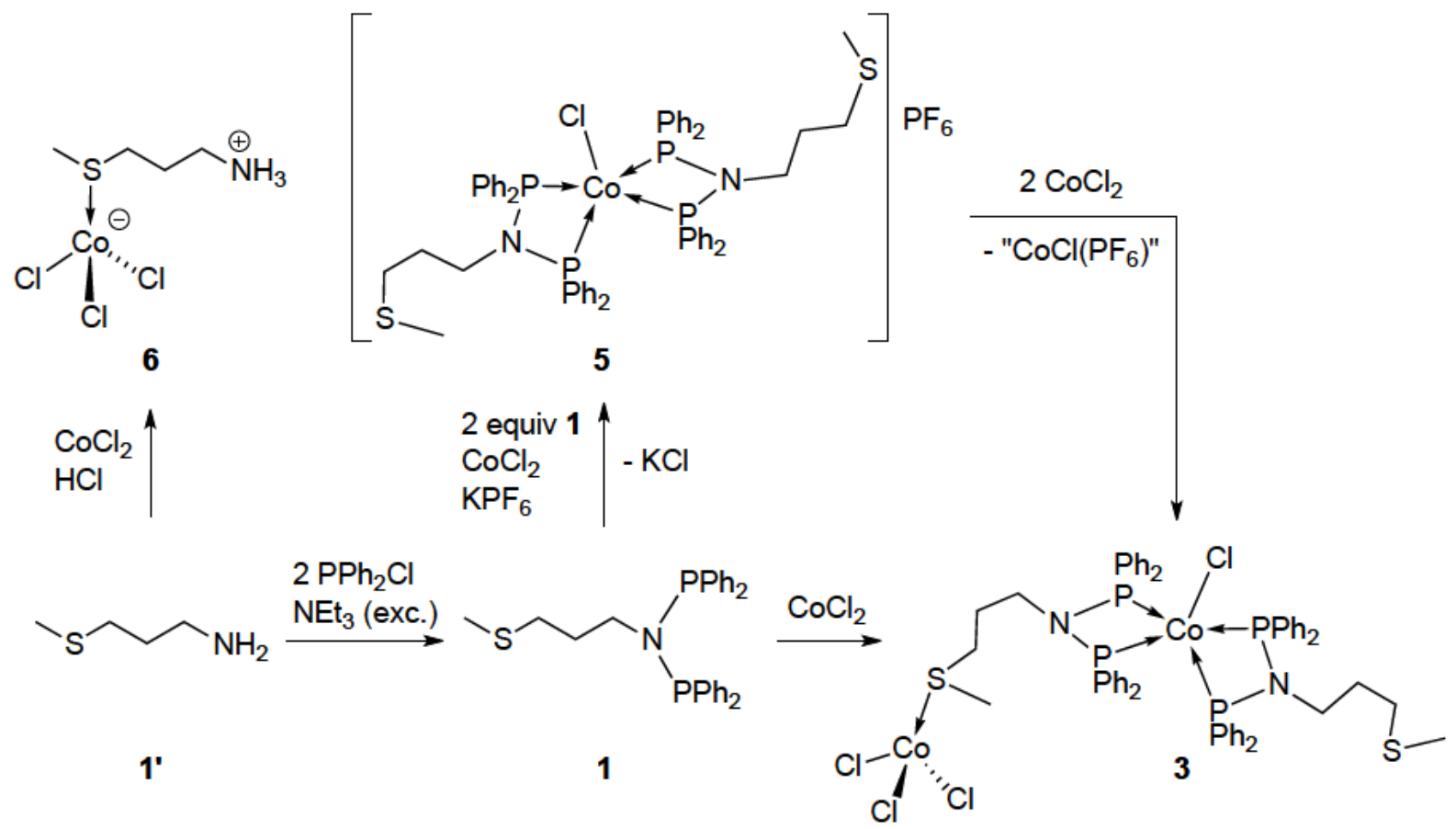

Scheme 2. Synthesis and structure of the zwitterionic complex 3 and its representative $\left[\mathrm{CoCl}(\mathbf{1})_{2}\right] \mathrm{PF}_{6}(\mathbf{5})$ and $\left[\mathrm{CoCl}_{3}(\mathrm{H1}\right.$ ') $](6)$ "fragments". 
Complex 5 was obtained in nearly quantitative yield by reaction of anhydrous $\mathrm{CoCl}_{2}$ with ligand 1 in a 1:2 metal/ligand ratio in the presence of excess $\mathrm{KPF}_{6}$ and was isolated as red crystals. Elemental and MS analyses were in agreement with its crystal structure (Figure 2). The structural parameters around the Co center (Co1) are, as expected, very close to those found for $\mathrm{Co} 1$ in complex $3 \cdot 2 \mathrm{CH}_{2} \mathrm{Cl}_{2}$ (selected bond lengths and angles are reported in Table 1). The cobalt(II) center is bis-chelated by two ligands $\mathbf{1}$, and adopts again a distorted trigonal bipyramidal coordination geometry, as quantified by a $\mathrm{S}\left(D_{3 \mathrm{~h}}\right)=2.47$ measure (Table $\mathrm{S} 10$ ), in which the base contains two phosphorus atoms from different ligands (P1, P3), with Co-P bond lengths of 2.240(1) (P1) and 2.264(1) $\AA$ (P3), and one chlorine [Co-Cl1 2.227(1) $\AA$ ] while two phosphorous donors occupy the apical positions and exhibit Co-P bond lengths close to those for the basal ones [Co1-P2 and Co1-P4 2.239(2) and 2.241(2) $\AA$, respectively]. The cationic charge on the cobalt center is balanced by an isolated $\mathrm{PF}_{6}$ anion. The major peak recorded in the ESI-MS spectrum of complex 5 was found at $\mathrm{m} / z 1040.2$ and attributed to the $\left[M-\mathrm{PF}_{6}\right]^{+}$fragment. The far-FT-IR spectrum of 5 was also recorded and compared with that of the zwitterionic complex $\mathbf{3}$ (see below).

Gratifyingly, the reaction of $\mathbf{5}$ with two equivalents of anhydrous $\mathrm{CoCl}_{2}$ also afforded the zwitterionic complex 3 , with concomitant formation of " $\mathrm{CoClPF}_{6}$ " (not isolated).

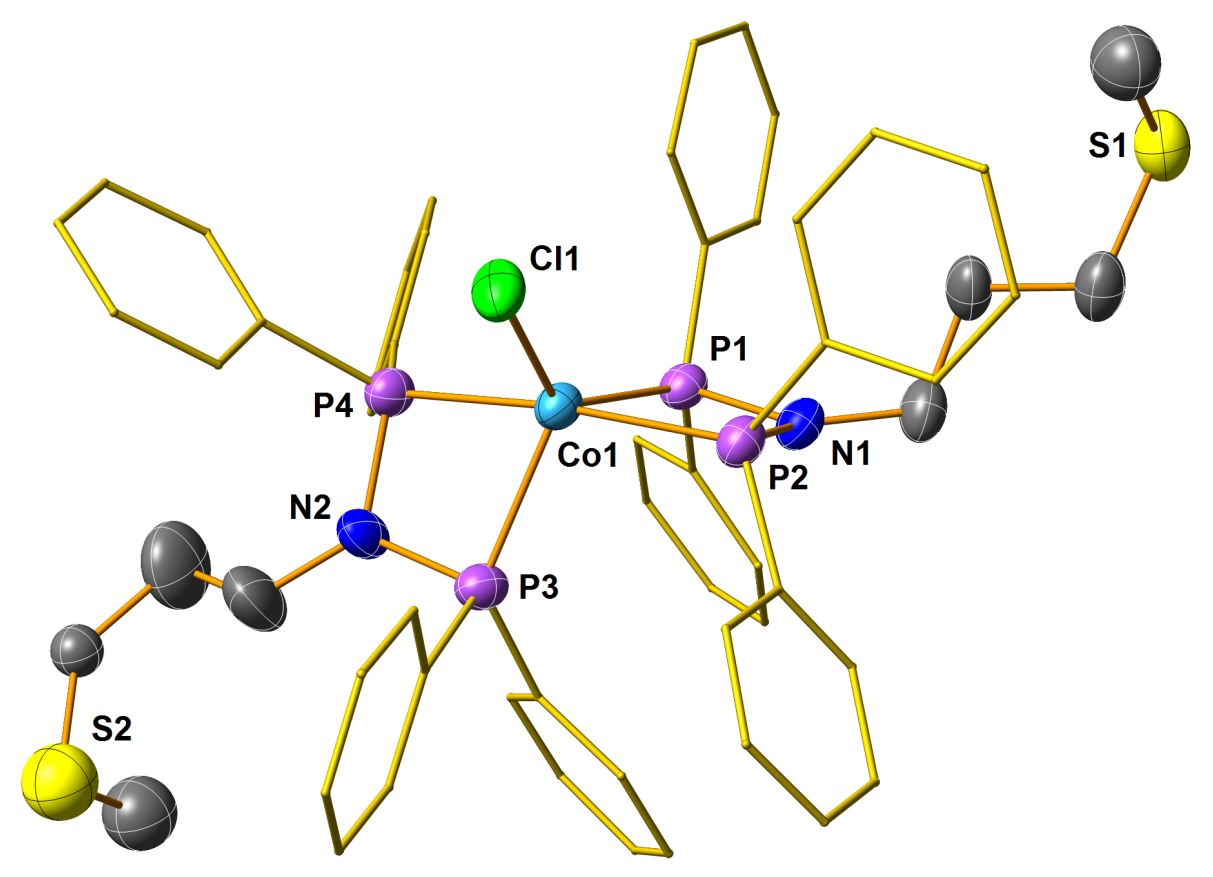


Figure 2. View of the molecular structure of the cationic complex in $\mathbf{5} \cdot \mathrm{CH}_{2} \mathrm{Cl}_{2}$. Counter ion, solvent molecule and hydrogen atoms omitted for clarity. Ellipsoids are represented at 50\% probability level. Selected bond lengths and angles are reported in Table 1.

The complex $\left[\mathrm{CoCl}_{3}\left(\mathrm{H1}^{\prime}\right)\right](\mathbf{6})\left(\mathbf{1}^{\prime}=\mathrm{NH}_{2}\left(\mathrm{CH}_{2}\right)_{3} \mathrm{SMe}\right)$ was obtained stepwise by $(i)$ addition of a $\mathrm{HCl}$ aqueous solution to a $\mathrm{CH}_{2} \mathrm{Cl}_{2}$ solution of 3-(methylthio)propylamine 1', the amine precursor to ligand $\mathbf{1}$, leading to the corresponding ammonium chloride (not isolated) and (ii) addition of $\mathrm{CoCl}_{2}$, which captured a chloride ion and completes its coordination sphere with the thioether donor function of the ligand. The structure of the zwitterionic complex 6 was confirmed by single crystal X-ray diffraction studies and, as expected, revealed structural parameters very similar to those of $\mathrm{Co} 2$ in complex $3 \cdot 2 \mathrm{CH}_{2} \mathrm{Cl}_{2}$ (Figure 3 and Table 1). The anionic cobalt(II) center has a distorted tetrahedral coordination geometry with $\mathrm{Co}-\mathrm{Cl}$ bond lengths ranging from 2.233(8) $(\mathrm{Cl} 2)$ to 2.264(8) $\AA(\mathrm{Cl} 3)$, close to those found in 3, and a Co1-S1 bond of 2.365(9) A, shorter than in complex 3 [Co2-S2 2.396(2) $\AA$ ].

Complex 6 was also characterized by EA, ESI-MS (major peak: $m / z 234.9$ attributed to $[\mathrm{M}-\mathrm{Cl}]^{+}$) and FT-IR spectroscopy (see below).

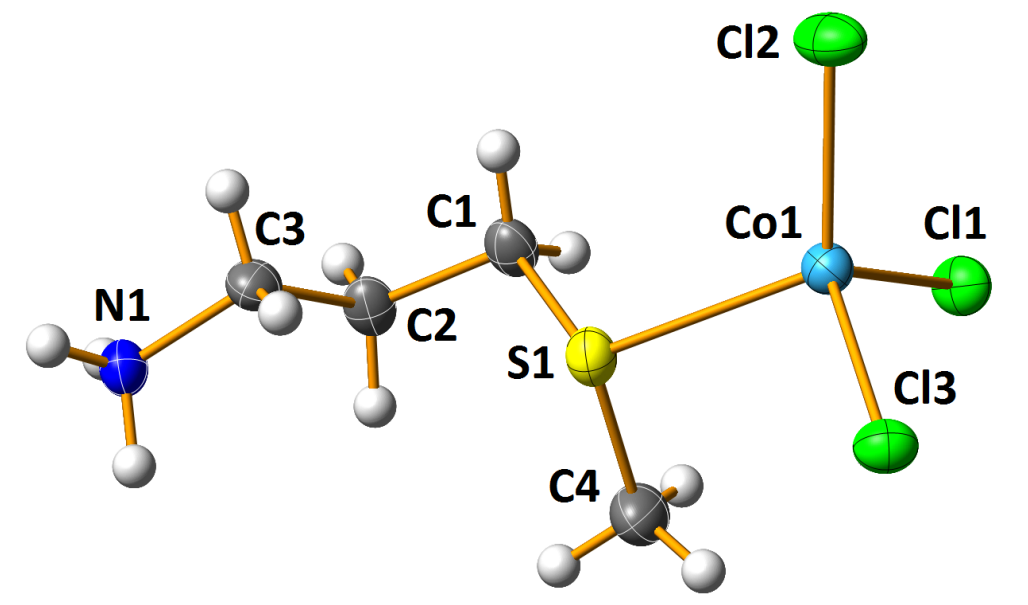

Figure 3. View of the molecular structure of $\left[\mathrm{CoCl}_{3}\left(\mathrm{H} \mathbf{1}^{\prime}\right)\right](\mathbf{6})\left(\mathbf{1}^{\prime}=\mathrm{NH}_{2}\left(\mathrm{CH}_{2}\right)_{3} \mathrm{SMe}\right)$. Ellipsoids are represented at 50\% probability level. Selected bond lengths and angles are reported in Table 1. 
Table 1. Selected bond lengths $(\AA)$ and angles (deg) in the solid-state structures of $3 \cdot 2 \mathrm{CH}_{2} \mathrm{Cl}_{2}$, $5 \cdot \mathrm{CH}_{2} \mathrm{Cl}_{2}, 6,7$ and $\mathbf{8}$.

\begin{tabular}{|c|c|c|c|c|c|c|c|}
\hline & $\mathbf{3} \cdot 2 \mathrm{CH}_{2} \mathrm{Cl}_{2}$ & $\mathbf{5} \cdot \mathrm{CH}_{2} \mathrm{Cl}_{2}$ & 7 & & 6 & & 8 \\
\hline Co1-P1 & $2.283(2)$ & $2.240(1)$ & $2.232(1)$ & & & & \\
\hline Co1-P2 & $2.248(2)$ & $2.239(2)$ & $2.223(1)$ & & & & \\
\hline Co1-P3 & $2.221(2)$ & $2.264(1)$ & $2.245(9)$ & & & & \\
\hline Co1-P4 & $2.233(2)$ & $2.241(2)$ & $2.223(1)$ & & & & \\
\hline Co1-Cl1 & $2.232(2)$ & $2.227(1)$ & $2.224(1)$ & & & & \\
\hline $\mathrm{Co} 2-\mathrm{S} 2$ & $2.396(2)$ & & & Col-S1 & $2.365(9)$ & Co1-Cl4 & $2.272(6)$ \\
\hline $\mathrm{Co} 2-\mathrm{Cl} 2$ & $2.246(2)$ & & & Co1-Cl1 & $2.251(8)$ & & $2.271(5)$ \\
\hline $\mathrm{Co} 2-\mathrm{Cl} 3$ & $2.236(2)$ & & & $\mathrm{Co} 1-\mathrm{Cl} 2$ & $2.233(8)$ & & $2.257(6)$ \\
\hline $\mathrm{Co} 2-\mathrm{Cl} 4$ & $2.242(2)$ & & & $\mathrm{Co} 1-\mathrm{Cl} 3$ & $2.264(8)$ & & $2.293(5)$ \\
\hline P1-Co1-P2 & $71.69(6)$ & $71.65(5)$ & $71.93(3)$ & S1-Co1-Cl1 & $108.3(3)$ & $\mathrm{Cl1}-\mathrm{Co} 1-\mathrm{Cl} 4$ & $105.7(2)$ \\
\hline P3-Co1-P4 & $71.33(7)$ & $71.32(5)$ & $72.20(3)$ & $\mathrm{S} 1-\mathrm{Co} 1-\mathrm{Cl} 2$ & 114.1(3) & $\mathrm{Cl} 2-\mathrm{Co} 1-\mathrm{Cl} 4$ & $110.7(2)$ \\
\hline P1-Co1-Cl1 & $119.5(7)$ & $134.8(6)$ & $127.6(4)$ & $\mathrm{S} 1-\mathrm{Co} 1-\mathrm{Cl} 3$ & $96.6(3)$ & $\mathrm{Cl} 3-\mathrm{Co} 1-\mathrm{Cl} 4$ & $106.8(2)$ \\
\hline P3-Co1-Cl1 & $128.0(7)$ & $118.8(6)$ & $123.9(4)$ & $\mathrm{Cl1}-\mathrm{Co} 1-\mathrm{Cl} 2$ & $113.5(3)$ & & $115.3(2)$ \\
\hline $\mathrm{S} 2-\mathrm{Co} 2-\mathrm{Cl} 2$ & $100.4(7)$ & & & $\mathrm{Cl1}-\mathrm{Co} 1-\mathrm{Cl} 3$ & $113.0(3)$ & & $108.6(2)$ \\
\hline $\mathrm{Cl} 2-\mathrm{Co} 2-\mathrm{Cl} 3$ & $117.9(8)$ & & & $\mathrm{Cl} 2-\mathrm{Co} 1-\mathrm{Cl} 3$ & $110.3(3)$ & & $109.4(2)$ \\
\hline P1-N1-P2 & $102.6(3)$ & $101.7(2)$ & $99.4(2)$ & $\mathrm{C} 1-\mathrm{S} 1-\mathrm{C} 4$ & $101.2(2)$ & $\mathrm{C} 1-\mathrm{S} 1-\mathrm{C} 7$ & $103.0(1)$ \\
\hline P3-N2-P4 & $99.0(3)$ & $101.7(2)$ & $100.2(2)$ & & & C8-S2-C14 & $104.6(1)$ \\
\hline
\end{tabular}

Our strategy consisting in the independent synthesis of mononuclear cobalt(II) complexes (5 and 6) with ligand 1 relevant to complex 3 being validated, it was applied to complexes based on ligand $\mathbf{2}$. We thus prepared and isolated the different moieties (7 and 8 ) related to complex 4 (Scheme 3).

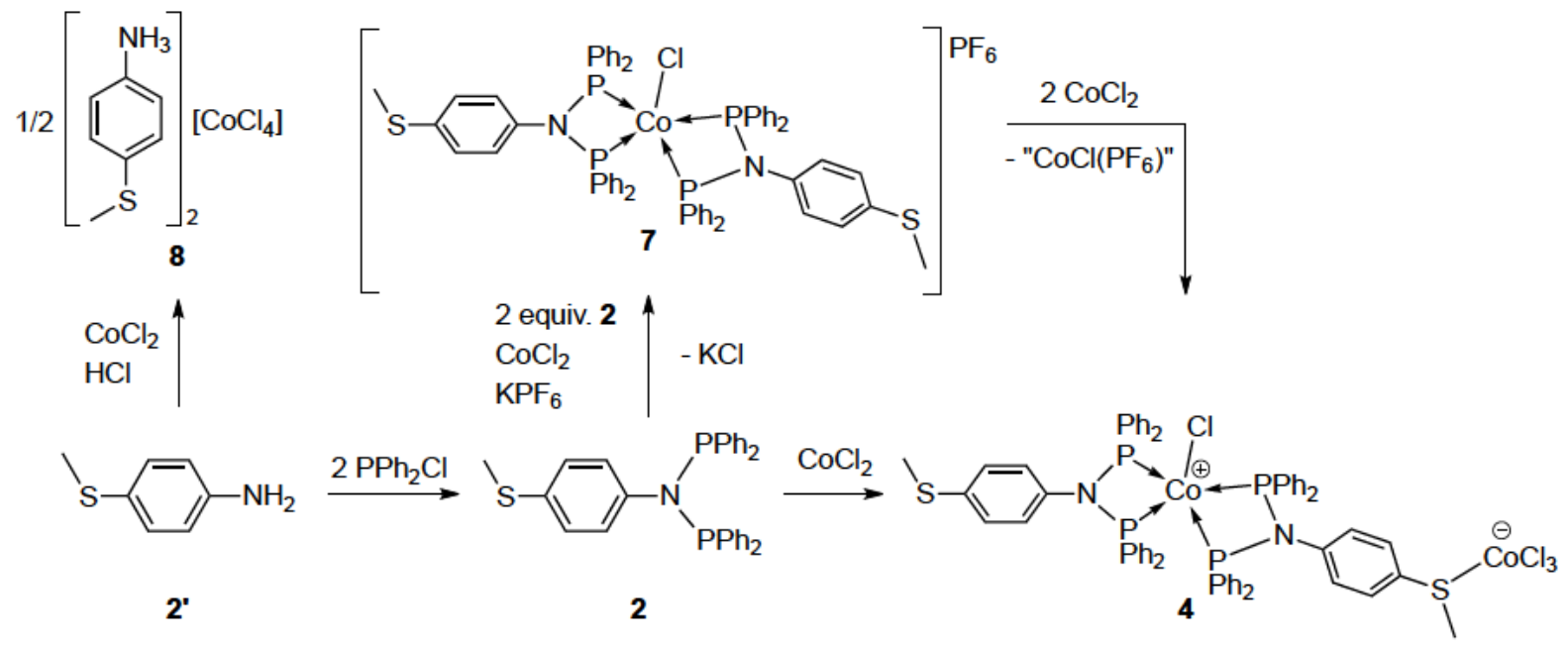


Scheme 3. Synthesis and proposed structure of complex 4 and the relevant "fragments" $\left[\mathrm{CoCl}(\mathbf{2})_{2}\right] \mathrm{PF}_{6}(\mathbf{7})$ and $\left[\mathrm{H}^{\prime}{ }^{\prime}\right]_{2}\left[\mathrm{CoCl}_{4}\right](\mathbf{8})$.

Similarly to complex 5, the cationic bis- $(P, P)$-chelated complex $\left[\mathrm{CoCl}(\mathbf{2})_{2}\right] \mathrm{PF}_{6}(\mathbf{7})$ was synthesized by reaction between anhydrous $\mathrm{CoCl}_{2}$ and ligand 2 , in a 1:2 metal/ligand ratio, in the presence of excess $\mathrm{KPF}_{6}$. Complex 7 was isolated after recrystallization as green crystals and characterized by EA, ESI-MS $\left(m / z 1108.2\left[M-\mathrm{PF}_{6}\right]^{+}\right)$and FT-IR spectroscopy. Moreover, its molecular structure was determined in the solid-state by X-ray diffraction analysis (Figure 4). As expected, the cationic cobalt(II) center has a distorted trigonal bipyramidal coordination geometry, as quantified by a $\mathrm{S}\left(D_{3 \mathrm{~h}}\right)=2.18$ measure (Table $\mathrm{S} 10$ ), in which the base contains two phosphorus atoms from two ligands (P1, P3) and is completed by one chlorine atom (C11), while the apical positions are occupied by the two other P atoms (P2, P4) from the chelates. Interestingly, the characteristic structural parameters, i.e. bond lengths and angles around the cationic cobalt center, are very similar to those found in the analogous complex 5 with ligand 1 (Table 1). As was observed for $\mathbf{5}$, addition of two equivalents of anhydrous $\mathrm{CoCl}_{2}$ to a $\mathrm{CH}_{2} \mathrm{Cl}_{2}$ solution of complex 7 led to the formation of complex 4 (evidenced by FT-IR and EA).

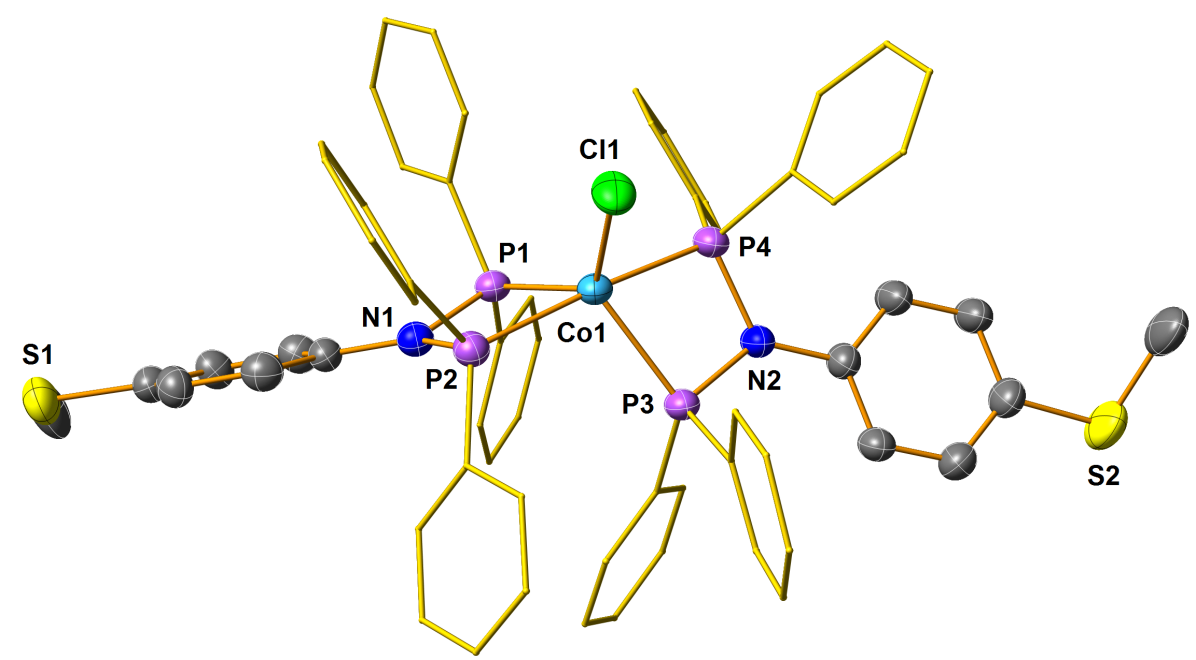

Figure 4. View of the molecular structure of the cationic complex in 7. Counter ion and hydrogen atoms omitted for clarity. Ellipsoids are represented at 50\% probability level. Selected bond lengths and angles are reported in Table 1.

Attempts to synthesize independently the anionic moiety potentially present in the zwitterionic complex 4 by a similar procedure to that used to access the $\mathrm{S}-\mathrm{CoCl}_{3}$ fragment of 
6, led surprisingly to a different outcome. Reaction of the amine $\operatorname{MeS}\left(p-\mathrm{C}_{6} \mathrm{H}_{4}\right) \mathrm{NH}_{2}$ (2'), precursor to ligand 2, with aqueous $\mathrm{HCl}$, followed by treatment with $\mathrm{CoCl}_{2}$, led to an intense blue powder (further identified as complex 8), along with some unreacted $\mathrm{CoCl}_{2}$. While the analytical results performed on this product were not consistent with the expected $\left[\mathrm{CoCl}_{3}\left(\mathrm{H}_{2}{ }^{\prime}\right)\right]$ formulation, its ESI-MS spectrum only revealed the peak corresponding to the ammonium chloride salt $\mathbf{2}^{\prime} \cdot \mathrm{HCl}$. The far-FT-IR spectrum of the isolated compound was also different from that of the zwitterionic complex $\left[\mathrm{CoCl}_{3}\left(\mathrm{H1} \mathbf{1}^{\prime}\right)\right](6)$ (see below). Fortunately, suitable crystals for X-ray diffraction analysis were obtained, and revealed that in the solidstate, the structure of complex $\mathbf{8}$ is composed of a $\mathrm{CoCl}_{4}$ dianion and two $\mathrm{H} 2$ ' ammonium cations (Figure 5). This observation is in accordance with the fact that unreacted $\mathrm{CoCl}_{2}$ was isolated and suggests that an ion-pair formulation for complex 4 , i.e. $\left[\mathrm{Co}(2)_{2}\right]\left[\mathrm{CoCl}_{4}\right]$, could be also reasonably envisaged, instead of a zwitterionic structure.
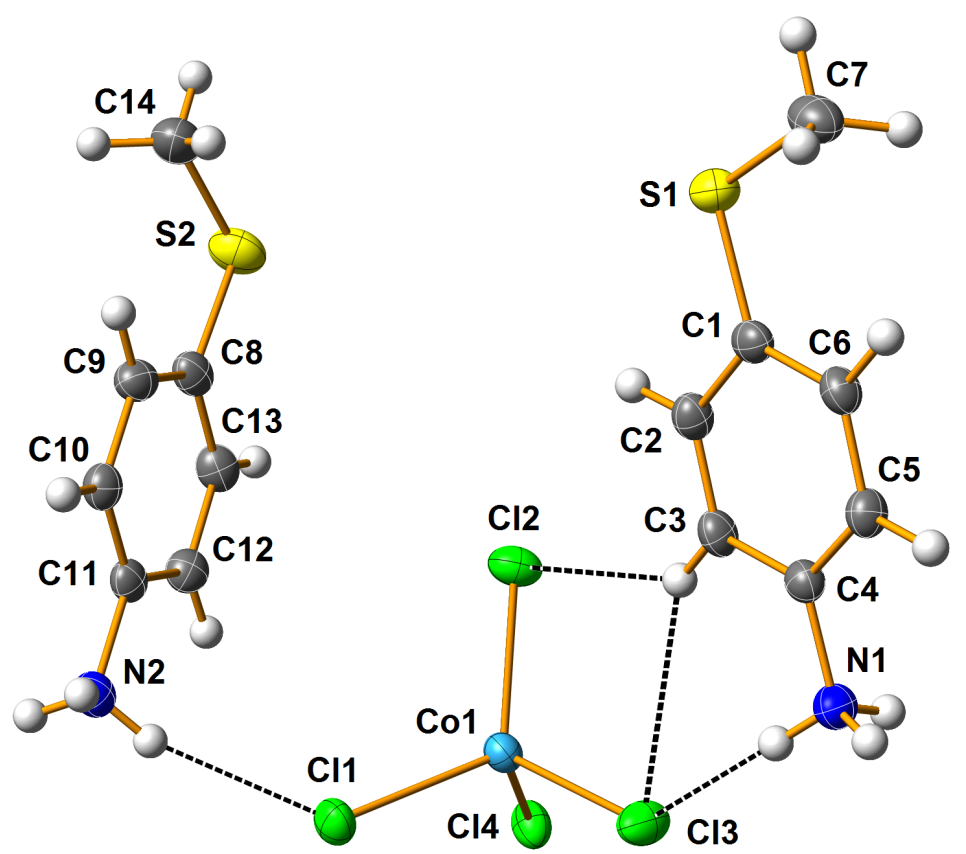

Figure 5. View of the molecular structure of 8. Ellipsoids are represented at 50\% probability level. Selected bond lengths and angles are reported in Table 1.

Attempts were made to synthesize trinuclear cobalt(II) complexes in which both thioether functions of ligand $\mathbf{1}$ or $\mathbf{2}$ would be coordinated to a $\mathrm{CoCl}_{2}$ or $\left[\mathrm{CoCl}_{3}\right]^{-}$moiety, by reacting (i) complex 3 (or 4) with 1 equiv $\mathrm{CoCl}_{2}$ or $\left[\mathrm{HNEt}_{3}\right]\left[\mathrm{CoCl}_{3}\right]$ and (ii) complex 5 (or 6) with 2 equiv $\left[\mathrm{HNEt}_{3}\right]\left[\mathrm{CoCl}_{3}\right]$ (generated in-situ), respectively. Unfortunately, these reactions did not lead to the expected compounds, but few crystals of the mixed-valent $\mathrm{Co}(\mathrm{II}) / \mathrm{Co}$ (III) 
polynuclear complexes, $\left[\mathrm{CoCl}_{2}(\mathbf{1})_{2} \mathrm{CoCl}_{3}\right]_{\mathrm{n}}(\mathbf{9})$ and $\left[\mathrm{CoCl}_{2}(\mathbf{2})_{2}\right]\left(\mathrm{H}^{\prime}\right)\left[\mathrm{CoCl}_{4}\right](\mathbf{1 0})\left(\mathrm{Scheme}^{4}\right)$ were isolated and their crystal structures are shown in the ESI (Figures S27 and S28).

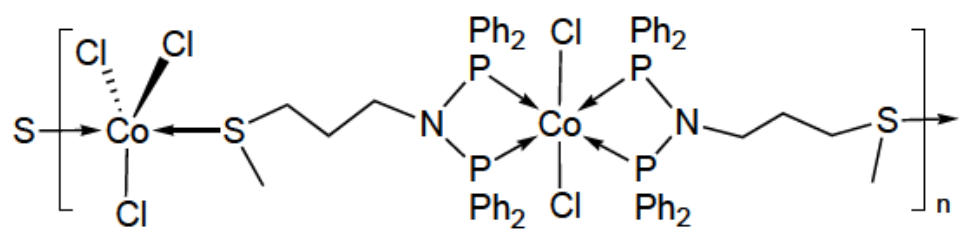

9

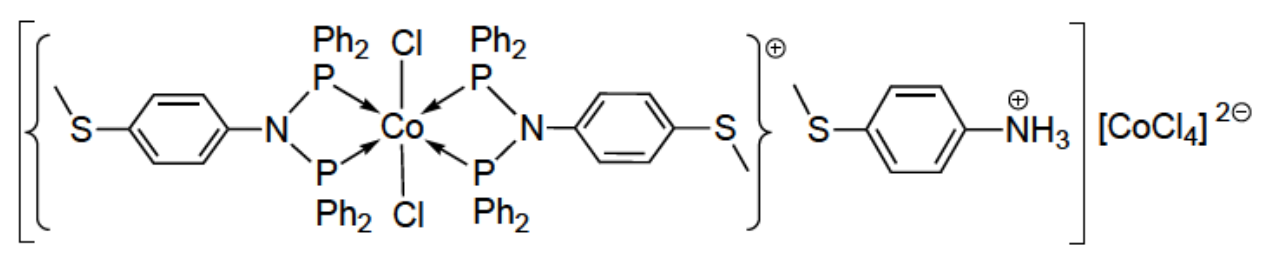

10

Scheme 4. The polynuclear complexes $\left[\mathrm{CoCl}_{2}(\mathbf{1})_{2} \mathrm{CoCl}_{3}\right]_{\mathrm{n}}(\mathbf{9})$ and $\left[\mathrm{CoCl}_{2}(\mathbf{2})_{2}\right]\left(\mathrm{H} 2\right.$ ') $\left[\mathrm{CoCl}_{4}\right]$ (10) (see Figures S27 and S28).

Since a rational synthesis could not be devised nor full analytical data obtained for complexes 9 and 10, they will not be discussed further. However, we note similarities between the coordination polymer 9 and 3 (the pentacoordinated $\mathrm{Co}$ (II) and the tetracoordinated Co(II) centers of 3 being replaced by a hexacoordinated $\mathrm{Co}$ (III) and a pentacoordinated $\mathrm{Co}$ (II) center, respectively) and between the cationic complexes in $\mathbf{1 0}$ and $\mathbf{7}$ (the pentacoordinated $\mathrm{Co}$ (II) center of the latter being replaced by a hexacoordinated $\mathrm{Co}(\mathrm{III})$ center).

\section{Far-FT-IR and UV-Visible Spectroscopic Data}

With the aim to validate our approach consisting in the synthesis of molecular synthons (here compounds 5-8) to clarify the structure of an unknown (complex 4) and more complex architecture (complexes 3 and 4), we studied their vibrational spectra in the far infrared region corresponding to the $v(\mathrm{Co}-\mathrm{Cl})$ vibrations, and their absorption electronic spectra in solution.

While the far-FT-IR spectrum of complex 3 exhibited four absorptions of medium intensity at $v=530$ (well separated from the other), 510, 490 and $480 \mathrm{~cm}^{-1}$ and one intense band at $v=320 \mathrm{~cm}^{-1}$ with weaker shoulders (Figure S1 in ESI), the spectrum of complex 4 exhibited three large and distinct bands at $v=557,526$ and $495 \mathrm{~cm}^{-1}$ and two intense bands at $v=307$ and $296 \mathrm{~cm}^{-1}$ with weak shoulders (Figure S5 in ESI). Both compounds also 
presented weak absorptions in the $430-360 \mathrm{~cm}^{-1}$ region. The complexity of these spectra encouraged us to compare the spectrum of each compound with those of their suggested fragments (5, 6 for $\mathbf{3}$ and 7, 8 for 4, Schemes 2 and 3, respectively).

As expected, the far-IR spectra of complexes 5 and $\mathbf{6}$, when superimposed to that of complex 3, showed significant similarities (Figure 6). The spectrum of 6 exhibits three absorptions at 320,305 and $289 \mathrm{~cm}^{-1}$ assigned to the distorted tetrahedral S-CoCl 3 moiety and their pattern is comparable to that found for $\mathbf{3}$, however shifted to lower wavenumbers (Figures S1 (3) and S3 (6) in ESI). Interestingly, none of these absorption bands was detected in the spectrum of $\mathbf{5}$. In contrast, various strong vibration bands between 550 and $480 \mathrm{~cm}^{-1}$ are present in both the spectra of $\mathbf{3}$ and $\mathbf{5}$ (Figures S1 (3) and S2 (5) in ESI).

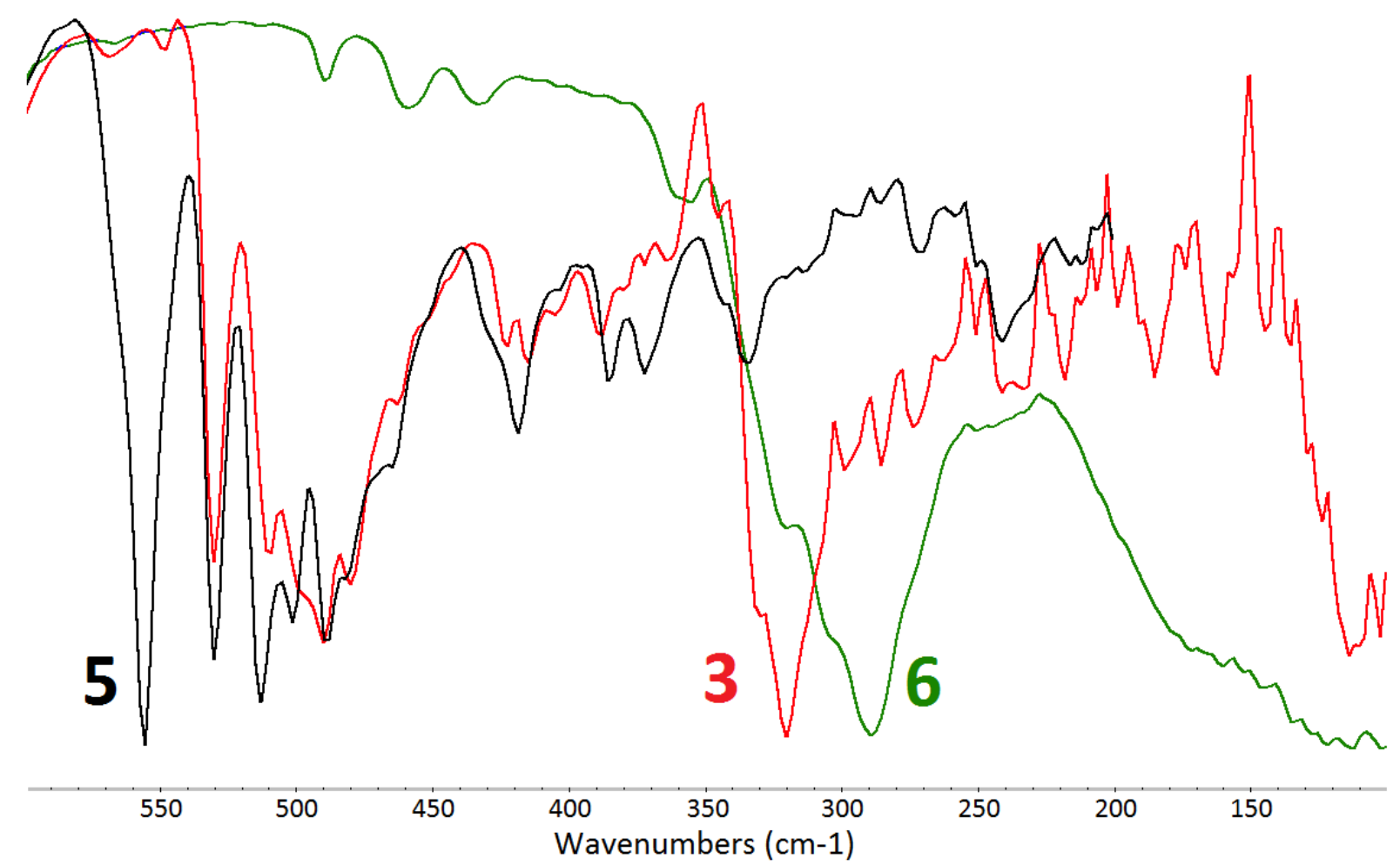

Figure 6. Superimposition of the IR spectra of complexes 3, 5 and $\mathbf{6}$ in the $600-100 \mathrm{~cm}^{-1}$ region.

A comparison between the far-FT-IR spectra of complexes 4 and 7 also revealed close similarities with four absorptions at 554, 526, 495 and $423 \mathrm{~cm}^{-1}$ for 4 and 556, 526, 492 and $425 \mathrm{~cm}^{-1}$ for 7 (Figures 7, and S5 (4) and S6 (7) in ESI). However, complex 4 exhibits strong and broad absorption bands centered at $295 \mathrm{~cm}^{-1}$, in contrast to 7. The spectrum of 8 exhibits three very intense, well separated absorptions at 322, 294 and $272 \mathrm{~cm}^{-1}$ (Figure S7 in ESI, the splitting of the $T$ mode expected for a perfectly tetrahedral $\left[\mathrm{CoC}_{4}\right]^{2-}$ dianion results from a 
lowering of the local symmetry). Compared with those of $\mathbf{4}$, the different shape of the bands could be due to intermolecular non-classical $\mathrm{H}-\mathrm{Cl}$ bonds or packing effects. In this spectral region, the spectrum of $\mathbf{6}\left(\mathrm{CoCl}_{3}\right.$ fragment $)$ also exhibits broad and poorly resolved absorption bands, with the most intense at $289 \mathrm{~cm}^{-1}$. Therefore, it is not possible to unambiguously conclude on the basis of FT-IR data about the presence of a $\mathrm{CoCl}_{4}$ or a $\mathrm{CoCl}_{3}$ fragment in complex 4.

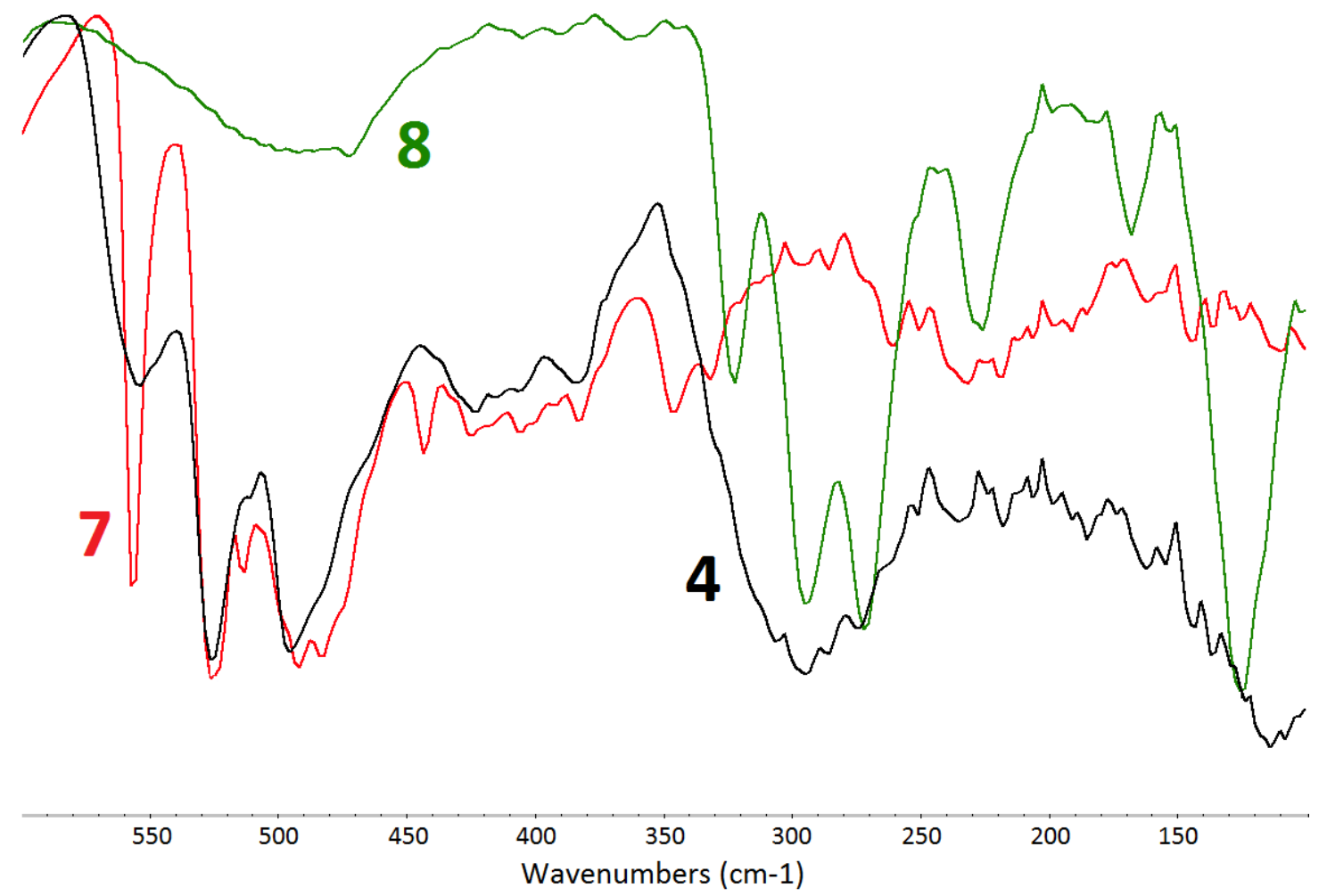

Figure 7. Superimposition of the IR spectra of complexes 4, 7 and 8 in the $600-100 \mathrm{~cm}^{-1}$ region.

We then recorded the UV-Vis spectra of all the isolated compounds with ligand $\mathbf{1}$. The spectra of the dinuclear zwitterionic complex $\mathbf{3}$ and of the mononuclear cationic complex $\mathbf{5}$ (both in $\mathrm{CHCl}_{3}$ ) presented the same characteristic absorption bands at 350, 375 and $470 \mathrm{~nm}$ (Figure 8). However, the spectrum of $\mathbf{3}$ exhibits a further absorption at $585 \mathrm{~nm}$ (in $\mathrm{CHCl}_{3}$ and THF) that is not present in the spectrum of 5, but a similar absorption $(\lambda 590 \mathrm{~nm})$ was recorded in the spectrum of the zwitterion 6 (in THF because of insolubility in $\mathrm{CHCl}_{3}$, Figure 8 insert), which is characteristic of a ${ }^{4} \mathrm{~T}_{1}(\mathrm{P}) \leftarrow{ }^{4} \mathrm{~A}_{2}$ transition split by spin-orbit coupling. ${ }^{19}$ These observations led us to conclude that the spectrum of 3 can be viewed as the superposition of the spectra of complexes $5\left(\mathrm{Co}^{+} \mathrm{Cl}(P, P)_{2}\right.$ fragment $)$ and $\mathbf{6}\left(\mathrm{SCo}^{-} \mathrm{Cl}_{3}\right.$ fragment $)$ 
and this encouraged us to study further the UV-Vis spectra of complexes $\mathbf{7}$ and $\mathbf{8}$, potential mononuclear building blocks of complex 4.

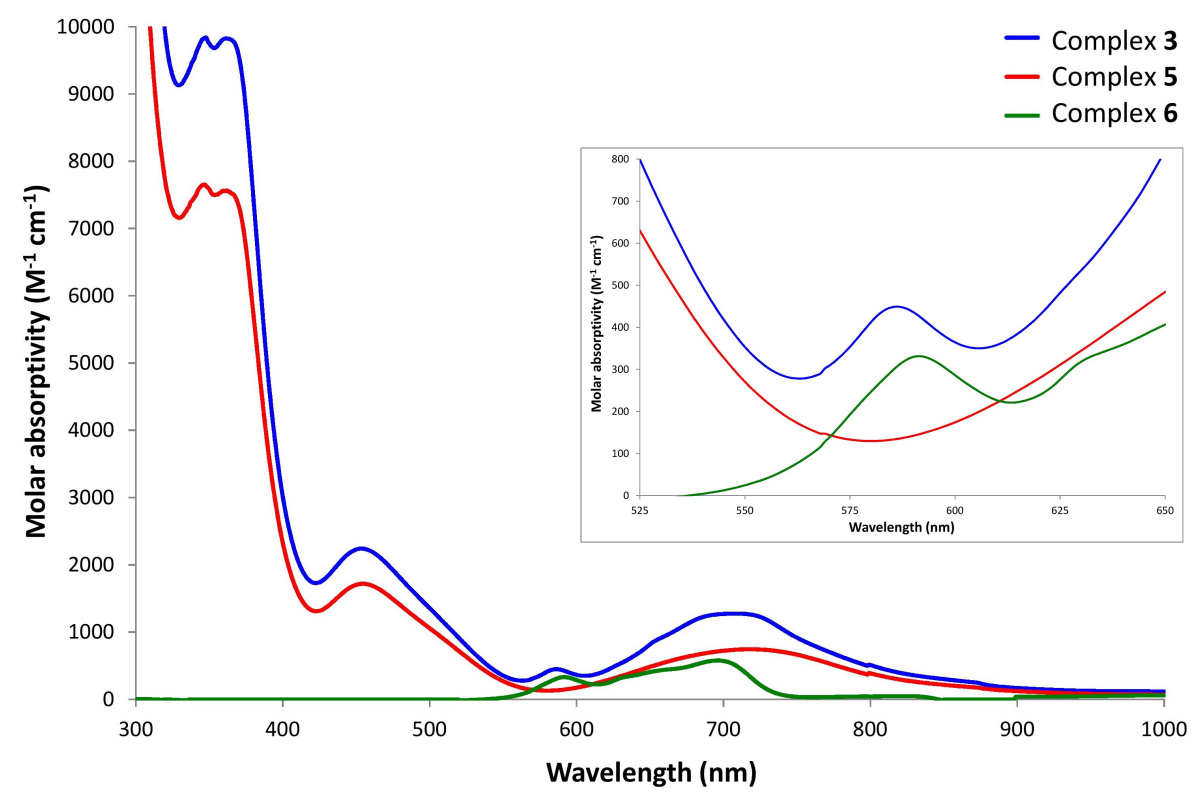

Figure 8. UV-Vis spectra of compounds $3\left(2 \cdot 10^{-4} \mathrm{M}\right.$ in $\left.\mathrm{CHCl}_{3}\right), \mathbf{5}\left(4 \cdot 10^{-4} \mathrm{M}\right.$ in $\left.\mathrm{CHCl}_{3}\right)$ and $\mathbf{6}$ $\left(3 \cdot 10^{-4} \mathrm{M}\right.$ in THF) and zoom in the 525-650 $\mathrm{nm}$ region, highlighting the fact that the spectrum of the dinuclear zwitterionic complex $\mathbf{3}$ is nearly the sum of those from the mononuclear complexes 5 and $\mathbf{6}$.

Interestingly, in the case of the complexes supported by ligand $\mathbf{2}$, we initially observed that 4 exhibited a different spectrum in $\mathrm{CHCl}_{3}$ and in THF, in contrast to 3 which has similar spectra in both solvents. While the spectrum of 4 in $\mathrm{CHCl}_{3}$ closely resembles those of complexes 7 (in $\mathrm{CHCl}_{3}$ ) and $\mathbf{3}$ (Figure S9 in ESI), with a very intense absorption band below $330 \mathrm{~nm}$, a large shoulder until $375 \mathrm{~nm}$ and two of lower intensity at 460 and $690 \mathrm{~nm}$, its spectrum in THF is clearly different (Figure 9). The strong absorptions below $330 \mathrm{~nm}$ remain present in the spectrum of 4 in THF, but instead of a shoulder, there is a strong, sharp absorption at $370 \mathrm{~nm}$. The most important differences are found at higher wavelengths, since the absorption at $460 \mathrm{~nm}$ for 4 and 7 in $\mathrm{CHCl}_{3}$ is not present in the spectrum of 4 in THF, while an absorption band of low intensity appeared at $585 \mathrm{~nm}$, which is also present in the spectrum of complex 8 in THF (Figure 9 insert). Noteworthy, the UV-Vis spectrum reported for the $\left[\mathrm{CoCl}_{3} \text { (THF) }\right]^{-}$anion exhibits the similar two characteristic absorption bands at 587 and $693 \mathrm{~cm}^{-1}$ (vs. 585 and $690 \mathrm{~cm}^{-1}$ for 4 and $\mathbf{8}$ ), which were ascribed to the d-d transition from the ground state ${ }^{4} \mathrm{~A}_{2}$ to the ${ }^{4} \mathrm{~T}_{1}(\mathrm{P})$ state. ${ }^{20}$ Altogether, the facts that complex 8 exhibits 
different spectra in $\mathrm{CHCl}_{3}$ and THF and that the spectra of complexes 4 and 8 (in THF) present exactly the same pattern in the $550-750 \mathrm{~nm}$ region than the $\left[\mathrm{CoCl}_{3}(\mathrm{THF})\right]^{-}$anion, are in favor of a zwitterionic form (vs. ion-pair, Chart 2) for the dinuclear complex 4, whose weakly-coordinated $\mathrm{CoCl}_{3}$ fragment would be displaced by THF. The UV-Vis spectrum of a pseudo-tetrahedral $\left[\mathrm{CoCl}(\mu-\mathrm{Cl})\left(\mathrm{Me}_{2}-\mathrm{cAAC}\right)\right]_{2}$ complex, formally presenting a $\mathrm{LCoCl}_{3}$ fragment, also exhibits a similar pattern, with two strong absorption bands around 580 and $650 \mathrm{~cm}^{-1} \cdot{ }^{21}$ The spectra of complexes 4 and $\mathbf{8}$ in THF present exactly the same pattern

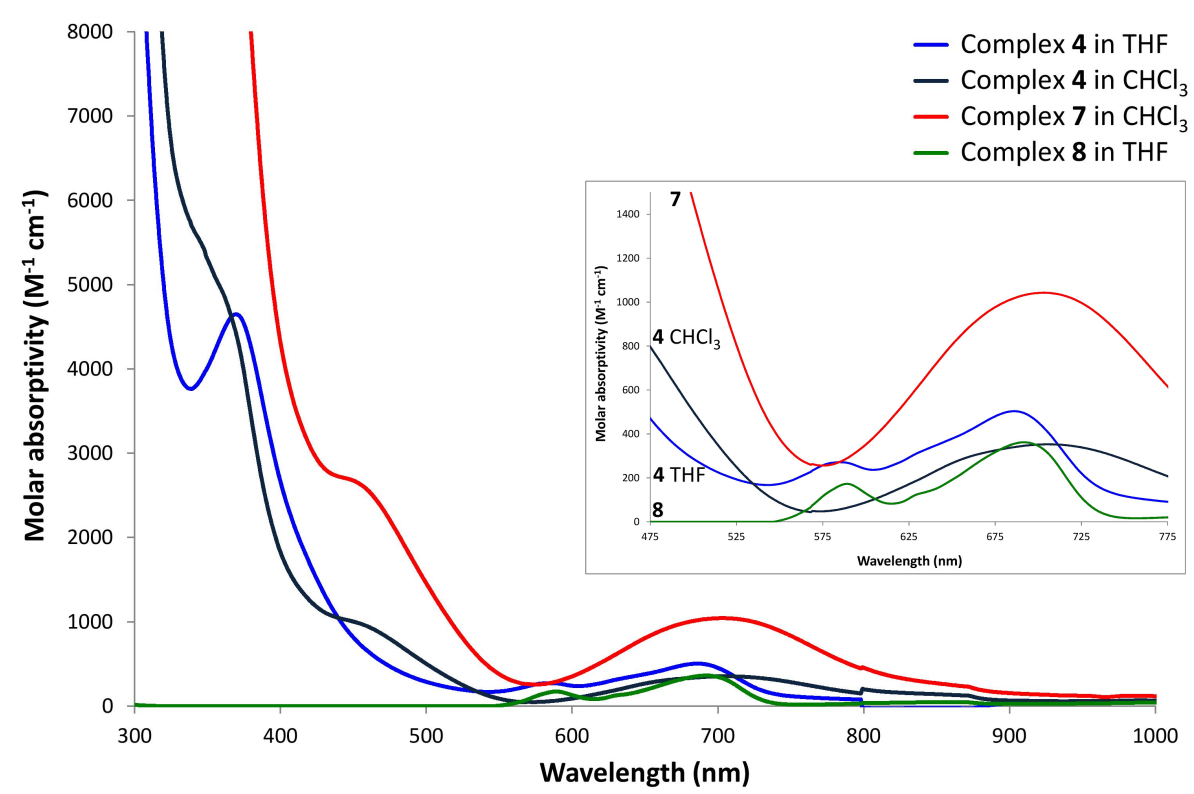

Figure 9. UV-Vis spectra of compounds $4\left(4 \cdot 10^{-4} \mathrm{M}\right.$ in THF and $\left.2 \cdot 10^{-4} \mathrm{M}^{\text {in }} \mathrm{CHCl}_{3}\right), 7\left(2 \cdot 10^{-4}\right.$ $\mathrm{M}$ in $\left.\mathrm{CHCl}_{3}\right)$ and $\mathbf{8}\left(4 \cdot 10^{-4} \mathrm{M}\right.$ in THF) and zoom in the $475-775 \mathrm{~nm}$ region.

The UV-Vis studies revealed clearly that the spectrum of the bis-cobalt complex 3 combines the different absorption bands observed for its constitutive mononuclear fragments 5 and 6, independently of the solvent used. With complexes supported by ligand 2, we observed that the spectrum recorded for complex 4 is solvent dependent and different to that of complex 3, while both couples of complexes $5 / 7$ and $6 / 8$ exhibit the same characteristic absorptions (Figures S9-11 in ESI). These elements do not allow us to conclude on the exact structure of complex 4: in a non-coordinating solvent, such as chloroform, it behaves like the cationic bis-chelate $\left[\mathrm{Co}^{+} \mathrm{Cl}(P, P)_{2}\right]$ complex 7, while in coordinating THF, it presents undoubtedly the absorptions recorded for complex $\mathbf{8}$.

\section{EPR Measurements}


The X-band EPR spectra of powder samples of complexes 5 and 7 recorded at $5 \mathrm{~K}$ are shown in Figure 10, together with their simulations. As reported in the literature, five coordinate Low-Spin (LS) cobalt(II) complexes have been found with soft phosphorus donor ligands. ${ }^{22}$ The fit parameters are consistent with a trigonal bipyramidal structure (Table 2). ${ }^{23}$ A low spin (LS) Co(II) $S=1 / 2$ doublet is suggested to have a weaker anisotropy than the corresponding $S$ $=3 / 2$ high spin (HS) species. Moreover, pulsed EPR indicates longer relaxation times, which are compatible with the usually well-separated energy levels encountered for the LS state. ${ }^{24}$ The spectral width is mostly due to the hyperfine interactions with the ${ }^{59}$ Co nucleus $(I=7 / 2)$ and the overall signal shape is well reproduced (Table 2).

Table 2. $g$-Tensor and hyperfine tensor components ( $h f c c$ 's, A) deduced by numerical simulations of the EPR spectra of powder samples of 5 and 7 recorded at $5 \mathrm{~K}$.

\begin{tabular}{|l|l|c|c|c|c|c|c|c|}
\hline$S$ & $g_{1}$ & $g_{2}$ & $g_{3}$ & $\begin{array}{c}\mathrm{A}_{1} \\
(\mathrm{MHz})\end{array}$ & $\begin{array}{c}\mathrm{A}_{2} \\
(\mathrm{MHz})\end{array}$ & $\begin{array}{c}\mathrm{A}_{3} \\
(\mathrm{MHz})\end{array}$ & $\begin{array}{c}\text { lwpp } \\
(\mathrm{mT})^{a}\end{array}$ \\
\hline $\mathbf{7}$ & $1 / 2$ & \multicolumn{2}{|c|}{2.057} & 2.288 & \multicolumn{2}{|c|}{19} & 120 & $\begin{array}{c}5.5 \\
\mathrm{G}+\mathrm{L}\end{array}$ \\
\hline $\mathbf{5}$ & $1 / 2$ & 2.040 & 2.087 & 2.350 & 19 & 19 & 140 & $\begin{array}{c}3.5 \\
\mathrm{G}+\mathrm{L}\end{array}$ \\
\hline
\end{tabular}

${ }^{a}$ lwpp corresponds to the peak-to-peak linewidth of the EPR signal with Gaussian (G) and Lorentzian (L) line shape broadening.

The X-band EPR spectra of powders of 6 and 8 recorded at $5 \mathrm{~K}$ (Figure 10) correspond to $\mathrm{Co}(\mathrm{II})$ in a HS quartet spin state. This is usually recognized by poorly resolved resonances, broadened by a combination of large $g$-anisotropy, sizable spin-orbit couplings and admixture of excited state character into the magnetic ground state. ${ }^{25}$ Two strategies may be considered to obtain visually satisfactory simulations of HS Co(II) EPR spectra. Both rely on an effective $S=1 / 2$ ground state. The positions of the resonances are then matched either by considering an axial $g$-tensor, hence introducing rhombicity of the zero-field slitting (ZFS), ${ }^{26}$ or by considering an axial ZFS and by tuning the anisotropy of the $g$-tensor. ${ }^{27}$ It is worth mentioning that, mathematically, one can often achieve a similarly satisfying visual simulation by using a $M_{\mathrm{S}}=3 / 2$ ground state and varying the rhombicity in both $g$ and ZFS, although this provides a wholly indeterminate set of solutions. It is noteworthy that the EPR signal extends well beyond the $g=2$ region at low temperature, so that more transitions than 
expected may be observed. ${ }^{28}$ In many instances, these "additional" lines appear at fields above $0.5 \mathrm{~T}$, so that partly out-of-range transitions may induce artifacts into the simulations. Simulations of the spectra for $\mathbf{6}$ and $\mathbf{8}$ (Table 3) are proposed while we are fully aware of all these difficulties. These simulations will serve as references for the spectral simulation of the bis-Co complexes described hereafter. The narrower peak-to-peak linewidth in the signal of 8 may express an isotropic tetrahedral surrounding of the Co nucleus in a $\mathrm{CoCl}_{4}$ environment while it was anisotropic tetrahedral in $6\left(\mathrm{CoCl}_{3} \mathrm{~S}\right)$.

Table 3. EPR parameters deduced by numerical simulations of the EPR spectra of powder samples of $\mathbf{6}$ and $\mathbf{8}$.

\begin{tabular}{|c|c|c|c|c|c|}
\hline & $S$ & $g_{\perp}$ & $g_{/ /}$ & $\begin{array}{c}\text { ZFS } \\
D\left(\mathrm{~cm}^{-1}\right)\end{array}$ & $\begin{array}{c}\text { lwpp } \\
(\mathrm{mT})^{a}\end{array}$ \\
\hline $\mathbf{8}$ & $3 / 2$ & 2.240 & 2.340 & $>1.5$ & $\begin{array}{c}18 \\
\mathrm{G}+\mathrm{L}\end{array}$ \\
\hline $\mathbf{6}$ & $3 / 2$ & 2.033 & 2.120 & $>1.5$ & $\begin{array}{c}65 \\
\mathrm{G}+\mathrm{L}\end{array}$ \\
\hline
\end{tabular}

${ }^{a}$ lwpp corresponds to the peak-to-peak linewidth of the EPR signal for Gaussian (G) and Lorentzian (L) line shape broadening.

The X-band EPR spectra of the powder samples of complexes 3 and $\mathbf{4}$ show both the LS and HS features (Figures S12 and 10, respectively) with $g_{\text {eff }}(\mathrm{HS})=5.83$ and $g_{\text {eff }}(\mathrm{LS})=$ 2.17 for 3 and $g_{\text {eff }}(\mathrm{HS})=5.24$ and $g_{\text {eff }}(\mathrm{LS})=2.11$ for 4 . The anisotropic EPR spectral parameters deduced from simulations are summarized in Table 4.

Table 4. EPR parameters deduced from simulations of the experimental spectra of a frozen solution of 3 and of a polycrystalline powder 4 recorded at $5 \mathrm{~K}$. 


\begin{tabular}{|l|c|c|c|c|c|c|c|c|c|c|c|}
\hline & \multicolumn{9}{|c|}{$S=1 / 2$} & \multicolumn{5}{c|}{$S=3 / 2$} \\
\hline & $g_{1}=g_{2}$ & $g_{3}$ & $\begin{array}{c}\mathrm{A}_{1}=\mathrm{A}_{2} \\
(\mathrm{MHz})\end{array}$ & $\begin{array}{c}\mathrm{A}_{3} \\
(\mathrm{MHz})\end{array}$ & $\begin{array}{c}1 \mathrm{wpp} \\
(\mathrm{mT})^{a}\end{array}$ & $\%$ & $g_{\perp}$ & $g_{/ /}$ & $\begin{array}{c}D \\
\mathrm{~cm}^{-1}\end{array}$ & $\begin{array}{c}\text { lwpp } \\
(\mathrm{mT})^{a}\end{array}$ & $\%$ \\
\hline $\mathbf{4}$ & 2.057 & 2.288 & 19 & 120 & $\begin{array}{c}31 \\
\mathrm{~L}\end{array}$ & 54 & 2.240 & 2.340 & $>1.5$ & $\begin{array}{c}58 \\
\mathrm{~L}\end{array}$ & 46 \\
\hline $\mathbf{3}$ & 2.058 & 2.410 & 50 & 180 & $\begin{array}{c}25 \\
\mathrm{G}+\mathrm{L}\end{array}$ & 50 & 2.300 & 2.433 & $>1.5$ & $\begin{array}{c}48 \\
\mathrm{G}+\mathrm{L}\end{array}$ & 50 \\
\hline
\end{tabular}

${ }^{a}$ lwpp corresponds to the peak-to-peak linewidth of the EPR signal with Gaussian (G) and Lorentzian (L) line shape broadening.

Numerical simulations satisfactorily accounted for a 1:1 ratio of LS and HS species for the binuclear species. Unfortunately, grain size effects were observed for a polycrystalline powder of 3, which resulted in an orientation-dependent EPR signal. Although the low-spin region of polycrystalline 3 clearly shows the hyperfine interaction with the $I=7 / 2{ }^{59} \mathrm{Co}$ (Figure S12 in ESI), grain size effects prevent a proper assessment of the LS Co $h f c c$. We did not try to attenuate these effects upon finer grinding, being more concerned with the sample stability (structural and chemical). To remove the underlying ambiguity, we have studied sample 3 in frozen solution (Figure 10). This study actually demonstrated the similarity of the LS Co EPR signals for complexes 3 and 6. EPR studies cannot firmly conclude regarding the possible magnetic exchange between the two Co centers. Accounting for the estimation of such exchange coupling from SQUID measurements (see below), the main conclusion is that the two remote Co magnetic centers are very weakly correlated $\left(J<1 \mathrm{~cm}^{-1}\right)$. At the energy scale of EPR, this is always within the strong exchange limit with $J>>$ A. 

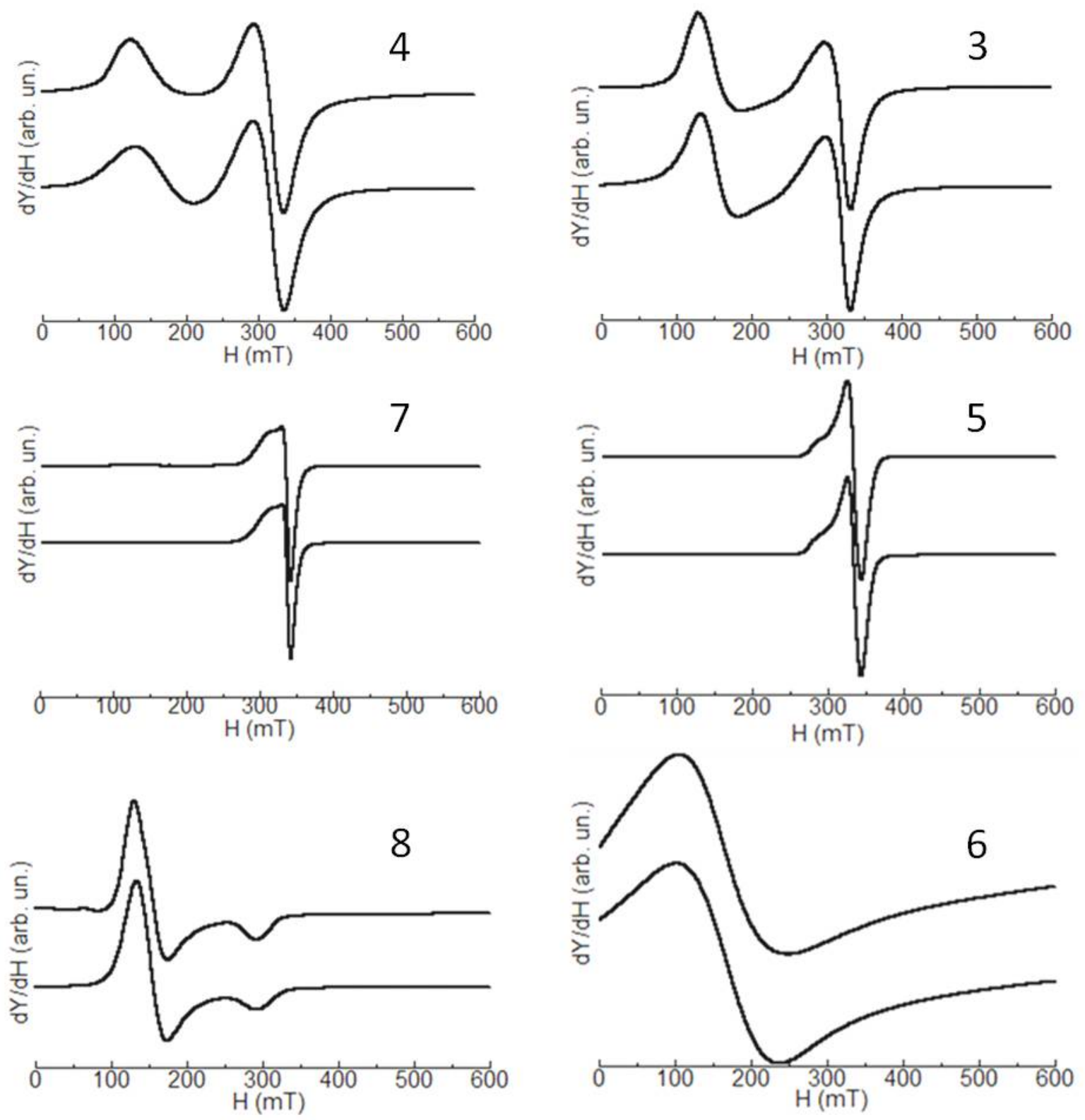

Figure 10. EPR spectra of powder samples of complexes 4-8 and of frozen solution of complex 3 recorded at $5 \mathrm{~K}$ : experimental (upper trace), simulation (lower trace).

\section{Magnetic Measurements}

We confronted the EPR results with the magnetic data on polycrystalline samples. Measurements were performed over the $2-300 \mathrm{~K}$ range under 1 or $10 \mathrm{kOe}$. Figure 11 illustrates the evolution of the $\chi_{M} \mathrm{~T}$ product with temperature for $\mathbf{5}$ and $\mathbf{7}$. Compound $\mathbf{5}$ shows Curie behavior above $20 \mathrm{~K}$, with a Curie value of $0.482(1) \mathrm{cm}^{3} \cdot \mathrm{K} \cdot \mathrm{mol}^{-1}$, while compound 7 shows Curie-Weiss behavior with $0.5663(3) \mathrm{cm}^{3} \cdot \mathrm{K} \cdot \mathrm{mol}^{-1}$ and $-1.7(1) \mathrm{K}$ (Figure S13 in ESI). Only a slight decrease of the $\chi_{M} T$ products is observed at low temperatures, in agreement with the low Weiss temperatures showing that the Co(II) ions are mostly uncorrelated. Isothermal 
magnetizations tend towards saturation values close to $1 \mu_{\mathrm{B}}$ (Figure S14 in ESI), thus supporting a low-spin $S=1 / 2$ ground state. Curves at 5 and $8 \mathrm{~K}$ are superimposed on the Brillouin curve for $g=2.119(1)$ and $g=2.345(1)$ for compounds 5 and 7, respectively. Compounds 5 and 7 show distorted trigonal bipyramidal $\mathrm{CoP}_{4} \mathrm{Cl}$ coordination geometries, with $C_{2}$ symmetry at most. For low-spin $\mathrm{Co}(\mathrm{II})$ in $T B P Y-\mathrm{ML}_{5}$ geometry, the resulting ${ }^{2} \mathrm{E}$ ' ground state is expected to have its orbital momentum quenched, but with a Landé $g$-value quite above the free electron value by spin-orbit mixing. Indeed, the effective $g$ values found for compounds 5 and 7, either from isothermal magnetizations or the Curie parameter (2.267(5) and 2.457(1) respectively) are in the range found by EPR for these compounds and for other low-spin $\mathrm{Co}^{\mathrm{II}} \mathrm{P}_{4} \mathrm{Cl}$ complexes. ${ }^{22,23,29}$ Intriguingly, isothermal magnetizations at $1.8 \mathrm{~K}$ deviate significantly from the Brillouin curve, and cannot be fitted with another Brillouin with reasonable values, which may be symptomatic of the onset of some intermolecular magnetic interactions between $\mathrm{Co}$ (II) centers that may not show zero-field splitting but are expected to have strongly anisotropic $g$ tensors.

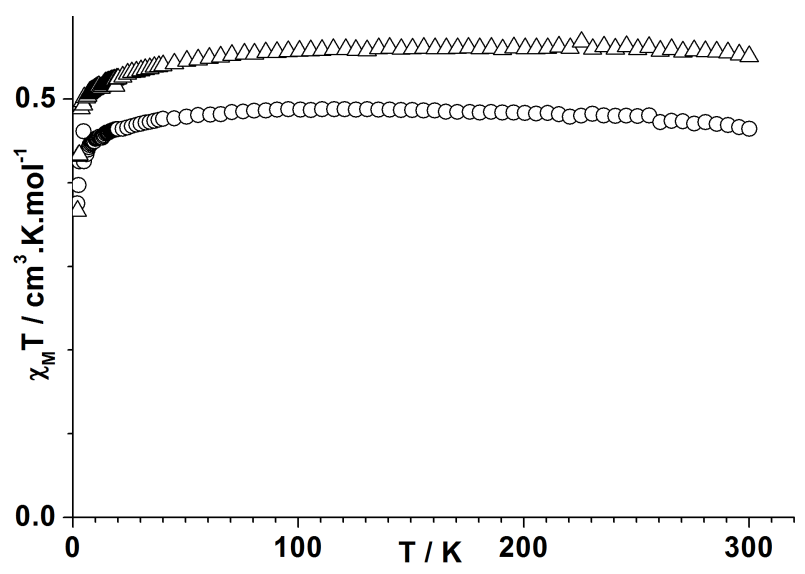

Figure 11. Variation of the $\chi_{M} \mathrm{~T}$ product with temperature measured under $10 \mathrm{kOe}$ for compounds 5 (circles) and 7 (triangles).

Figure 12 shows the evolution of the $\chi_{M} T$ product with temperature for $\mathbf{6}$ and $\mathbf{8}$. For both compounds, temperature-independent paramagnetic (TIP) contributions have to be taken into account, a common feature for tetrahedral $\mathrm{d}^{7} \mathrm{Co}(\mathrm{II})$ compounds, ${ }^{30}$ with a reasonable TIP value of $450 \cdot 10^{-6} \mathrm{~cm}^{3} \cdot \mathrm{mol}^{1}$ for compound 6. The latter shows straightforward Curie-Weiss behavior above $50 \mathrm{~K}$, with parameter values of 2.161(2) $\mathrm{cm}^{3} \cdot \mathrm{K} \cdot \mathrm{mol}^{1}{ }^{1}$ and $-3.0(3) \mathrm{K}$ (Figure $\mathrm{S} 15$ in ESI), in agreement with largely uncorrelated tetrahedral $\mathrm{Co}(\mathrm{II})$ ions in a ${ }^{4} \mathrm{~A}_{2}$ ground state, ${ }^{31,32,33,34,35}$ with a spin-only Landé factor $g=2.147(2)$, significantly larger than the free- 
electron value. The latter and the high TIP values are expected because of the mixing of the ground state with the low-lying ${ }^{4} \mathrm{~T}_{2}$ state issued from the same ${ }^{4} \mathrm{~F}$ atomic term. ${ }^{36}$ Below $50 \mathrm{~K}$, a significant decrease of the $\chi_{M} \mathrm{~T}$ product is observed down to $2 \mathrm{~K}$, in agreement with the observed negative Curie-Weiss temperature. Typical nesting behavior is observed in lowtemperature isothermal magnetization measurements (Figure S16 in ESI), showing the presence of antiferromagnetic interactions or/and single-ion magnetic anisotropy. Simulations taking into account only single-ion anisotropy proved unsatisfactory to simulate the magnetic behavior observed, all the more so since rhombicity on $g$ and/or the zero-field splitting cannot be reliably extracted from a powder measurement. The crystalline structure shows close contacts between chlorine and cobalt atoms of neighboring complexes, forming effectively pairs of complexes in the structure (Figure S17 in ESI). Using a simple dinuclear model with single-ion anisotropy allows for an acceptable simulation of both $\chi_{M} \mathrm{~T}$ and isothermal magnetization curves with the following parameters: $g=2.147, J=-0.4 \mathrm{~cm}^{-1}, D=+7 \mathrm{~cm}^{-1}{ }^{37}$ The interaction parameter agrees with the $-0.8 \mathrm{~cm}^{-1}$ value deduced from the Curie-Weiss temperature using the mean-field approach. ${ }^{38}$ Easy-axis single-ion anisotropies $(D<0)$ led to a worse agreement at low temperature for the $\chi_{M} \mathrm{~T}$ curve. The resulting effective $g$ factor value is above the average value of 2.062 found by EPR on a powder sample of $\mathbf{8}$. Some discrepancy between single-ion anisotropy values had to be expected given the inherent uncertainty for their determination from powder values.

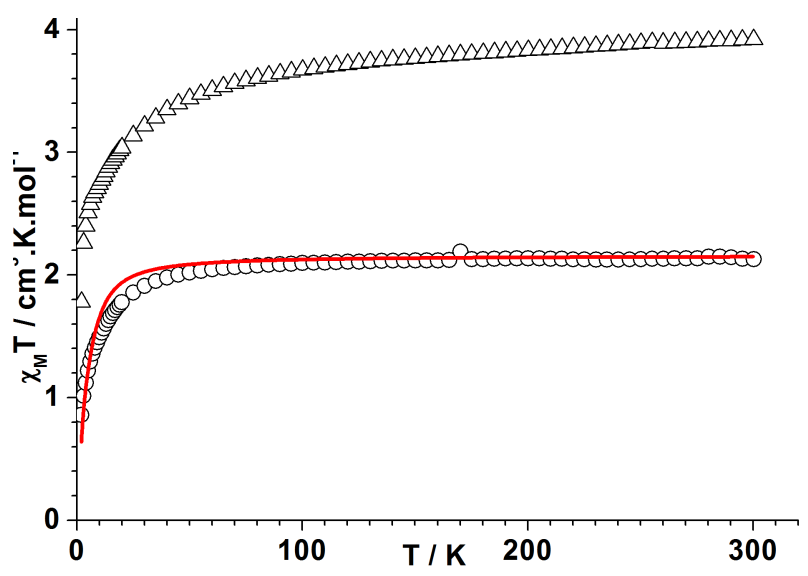

Figure 12. Variation of the $\chi_{M} \mathrm{~T}$ product with temperature measured under $1 \mathrm{kOe}$ for compounds 6 (circles) and 8 (triangles), with the simulated curve (red line), for $2 S=3 / 2$ spins in AF interaction, with $g=2.147, J=-0.4 \mathrm{~cm}^{-1}$ and $D=+7 \mathrm{~cm}^{-1}$. 
For compound 8 (Figure 12), even with a strong TIP contribution of $600 \cdot 10^{-6} \mathrm{~cm}^{3} \cdot \mathrm{mol}^{-1}$, as observed in other salts containing a tetrahedral $\mathrm{CoCl}_{4}{ }^{2-}$ anion, ${ }^{30,36}$ the $\chi_{\mathrm{M}} \mathrm{T}$ value still increases at high temperatures. A TIP value of $1500 \cdot 10^{-6} \mathrm{~cm}^{3} \cdot \mathrm{mol}^{1}$ would be required to account for the high temperature behavior, value that would imply a ${ }^{4} \mathrm{~T}_{2}$ excited state lying at unphysical low energy. ${ }^{39}$ Nevertheless, a Curie-Weiss law gives a satisfactory fit above $50 \mathrm{~K}$ (Figure S15 in ESI), with values of $4.04 \mathrm{~cm}^{3} \cdot \mathrm{K} \cdot \mathrm{mol}^{-1}$ and $-10.1 \mathrm{~K}$, depending on the TIP contribution used. These values support again tetrahedral $\mathrm{Co}(\mathrm{II})$ ions with a ${ }^{4} \mathrm{~A}_{2}$ ground state, but with an unusually high spin-only Landé factor $g=2.9$. The low-temperature behavior parallels that observed for compound 6 (Figure 12), with no maximum observable at low temperature on the susceptibility curve, but with an isothermal magnetization that does not seem to be close to saturation even at $1.8 \mathrm{~K}$ and $70 \mathrm{kOe}$ (Figure S16 in ESI). A close examination of the crystal packing of $\mathbf{8}$ shows that the $\mathrm{CoCl}_{4}{ }^{2}$ - ions form layers parallel to the (ac) plane, which are separated along the $b$ axis by the ammonium moieties (Figure S18 in ESI). The arrangement of the anions within the layers is close to a 2D honeycomb lattice, with close $\mathrm{Cl} \cdots \mathrm{Cl}$ contacts of about $4 \AA$. The anomalous magnetic behavior observed may thus be accounted for by correlation effects within those layers between the strongly anisotropic tetrahedral $\mathrm{Co}(\mathrm{II}) .{ }^{40}$ Its correct modeling would require further anisotropic measurements on single crystals that are outside the scope of this study.

Figure 13 reports the $\chi_{M} T$ product evolution with temperature for 3 and $\mathbf{4}$. It is readily seen that both compounds show very similar characteristics, with Curie-Weiss behavior above $20 \mathrm{~K}$ (Figure S19 in ESI), and parameters of $3.408(3) \mathrm{cm}^{3} \cdot \mathrm{K} \cdot \mathrm{mol}^{-1}$ and $-4.1(2) \mathrm{K}$ and $3.147(2) \mathrm{cm}^{3} \cdot \mathrm{K} \cdot \mathrm{mol}^{-1}$ and $-3.0(1) \mathrm{K}$, respectively. For both compounds, TIP contributions were taken into account, with a reasonable value of $350 \cdot 10^{-6} \mathrm{~cm}^{3} \cdot \mathrm{mol}^{-1}$ for 4 while 3 showed some slight contamination with ferromagnetic impurities, which could not be deconvoluted from the TIP contribution.

As indicated above, only for compound $\mathbf{3}$ is the solid state structure clearly established, and one could anticipate magnetic properties for $\mathbf{3}$ close to the sum of those of compounds $\mathbf{5}$ and 6. A comparison of the respective $\chi_{M} T$ products readily shows that although this is the case, in agreement with one low-spin Co(II) in trigonal bipyramidal coordination environment and one high-spin $\mathrm{Co}$ (II) with tetrahedral coordination, the single-ion properties vary somewhat, in agreement with the differences seen in the powder EPR spectra of compounds $\mathbf{3}$, 5 and 6. For 4, the $\chi_{M} \mathrm{~T}$ value at high temperature of $3.1 \mathrm{~cm}^{3} \cdot \mathrm{K} \cdot \mathrm{mol}^{-1}$ is quite close to the sum 
of corresponding values for compounds 7 and 6 at $2.7 \mathrm{~cm}^{3} \cdot \mathrm{K}^{\prime} \mathrm{mol}^{-1}$, indicating that here also the preferred formulation would be one low-spin $\mathrm{Co}(\mathrm{II})$ with trigonal bipyramidal coordination and one high-spin Co(II) with tetrahedral coordination.

For both compounds, a strong decrease of the $\chi_{M} \mathrm{~T}$ product is observed below $50 \mathrm{~K}$, but without any corresponding peak in the susceptibility curve, which indicates that any antiferromagnetic interaction is of low magnitude. Indeed, the structure of compound $\mathbf{3}$ does not evidence obvious interaction pathways. The decrease observed is thus caused mainly by the zero-field splitting of the ${ }^{4} \mathrm{~A}_{2}$ ground state of the tetrahedrally coordinated $\mathrm{Co}$ (II) ions. Though the problem is largely overparametrized, considering axially anisotropic $g$ tensors for both $\mathrm{Co}(\mathrm{II})$ ions, the zero-field splitting and a small intramolecular interaction between both $\mathrm{Co}(\mathrm{II})$ ions, reasonable sets of parameters can be found ${ }^{41}$ that simulate the overall behavior of both $\chi_{M} T$ and isothermal magnetization curves (Figures 13 and S20-S21 in ESI). We used the $g$ factors found by EPR for the pentacoordinated low-spin Co(II), and adjusted accordingly the $g$ factor for the tetrahedral $\mathrm{Co}(\mathrm{II})$, with an arbitrary ratio $g_{\perp} / g_{/ /}$fixed at 1.1 for both compounds (this ratio corresponds to that observed by EPR for the high-spin Co(II) in compound 4). In both cases, using easy-axis zero-field splitting led to worse simulations. The parameters found for compound 3 were: $J=-0.3 \mathrm{~cm}^{-1}, S=1 / 2, g_{\perp}=2.135$ and $g_{/ /}=2.402, S=$ $3 / 2, g_{\perp}=2.401, g_{/ /}=2.641$ and $D=+15 \mathrm{~cm}^{-1}$; and for compound $4: J=-0.4 \mathrm{~cm}^{-1}, S=1 / 2, g_{\perp}$ $=2.057$ and $g_{/ /}=2.288, S=3 / 2, g_{\perp}=2.31, g_{/ /}=2.541$ and $D=+10 \mathrm{~cm}^{-1}$.

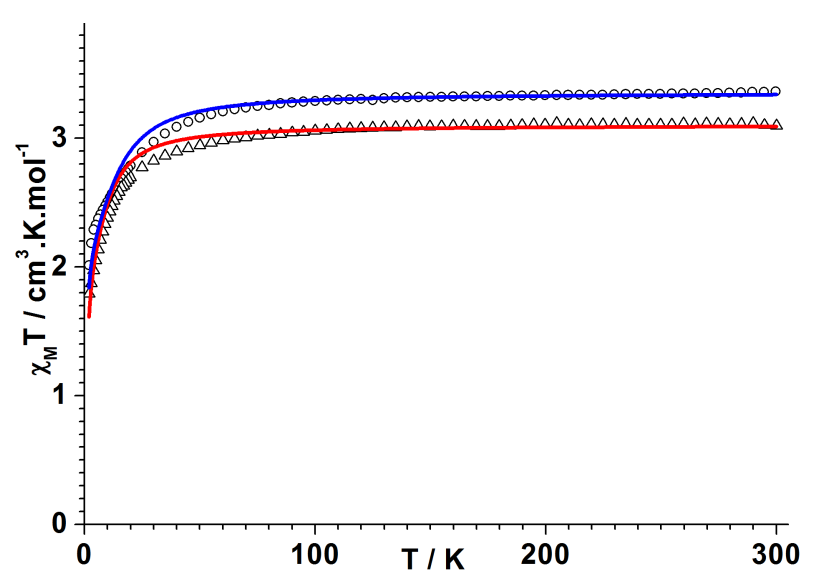

Figure 13. Variation of the $\chi_{M} \mathrm{~T}$ product with temperature measured under $1 \mathrm{kOe}$ for compounds 3 (black circles) and 4 (black triangles), and simulated curves (blue and red curves respectively) for the interacting $\{1 / 2 ; 3 / 2\}$ spin system (see text for parameters). 


\section{Theoretical DFT Calculations}

DFT calculations using the ADF package were performed to determine the geometries and the electronic structures of the complexes. Geometry optimizations were performed starting from the X-ray structures. In all cases, we found that spin contamination was negligible. For comparison, we first computed mononuclear complexes, viewed as building blocks of the dinuclear complexes. Several conformations for 5 and 7 were considered but only one has been optimized where the phenyl rings are roughly parallel to the P-N-P planes for 7 and the positions of the aliphatic chains for $\mathbf{5}$ are consistent with the X-ray structure. As established experimentally, the Col atom in 5 and 7 has an $S=1 / 2$ ground state, and therefore the structures were optimized as a doublet. The calculated geometries for $\mathbf{5}$ and $\mathbf{7}$ are similar to the arrangement of the ligands found in the X-ray structures. Relevant computed geometrical parameters are given in Table S2 (ESI) and compared to experimental values. The resulting bond lengths and angles are similar to those found experimentally. The largest deviation concerns the computed Co-P bond distances, which are $c a .0 .01-0.1 \AA$ longer than the observed values. The size of the molecules prevented optimization with larger basis sets or higher theory level methods to obtain more accurate values. The coordination sphere around the $\mathrm{Co} 1$ atom is distorted trigonal bipyramidal, with $\mathrm{S}\left(D_{3 \mathrm{~h}}\right)$ of 2.25 and 2.32 respectively, quite close to experimental values (2.47 and 2.18) (Table S10). The arrangement of the phenyl moieties and carbon chains are quite well reproduced for $\mathbf{7}$ and $\mathbf{5}$, respectively. As shown in Figure $14 \mathrm{~b}$ for $\mathbf{5}$, the spin density is exclusively centered on the cobalt cation, with very small contributions from the chlorine and phosphorus atoms. This spin density is mostly generated by the molecular orbital (SOMO) given in Figure $14 \mathrm{a}$ which is $\pi$-antibonding between the Co1 $3 \mathrm{~d}$ orbitals and the chlorine and phosphorus atoms. The situation is almost identical for 7, with a spin density again mostly localized on the cation. However, the associated SOMO shows some delocalization through the $\pi$ system of the phenyl rings. Finally, the different substituents on nitrogen have a slight influence on the electronic structure. The EPR parameters were also calculated to evaluate the $g$ tensors through a single point at the B3LYP level of DFT with the ORCA package on the ADF optimized geometries. The calculated values are listed in Table S3 (ESI). The simulation of the spectra indicated a more rhombic $g$ tensor for 5 than for $\mathbf{7}$, which is axial with $g_{\|}>g_{\perp}$. These results are similar to those reported on triphosphine complexes and support the assignment of a trigonal bipyramidal structure with a mixed $d_{\mathrm{x}^{2}-\mathrm{y}^{2}} / d_{\mathrm{xy}}$ ground state. ${ }^{42}$ This is consistent with the spin density map calculated for the low spin mononuclear complexes localized on the trigonal 
equatorial plane. The computed $g$ tensors obtained for both compounds are almost axial and reproduce quite satisfactory the EPR data for 7. A more important discrepancy is observed for 5 that is attributed to the absence of the surrounding medium, i.e. calculations were performed on the gas phase.

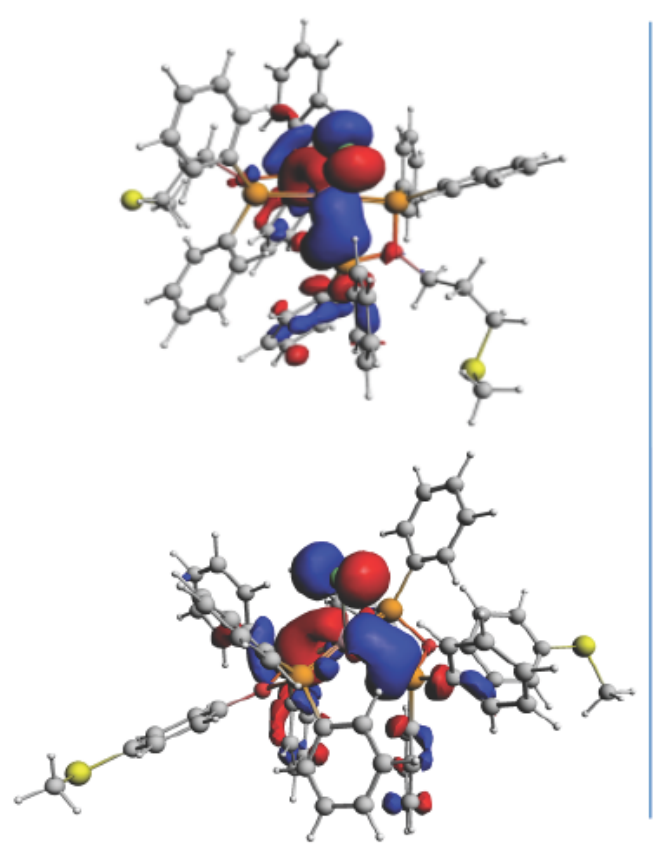

a
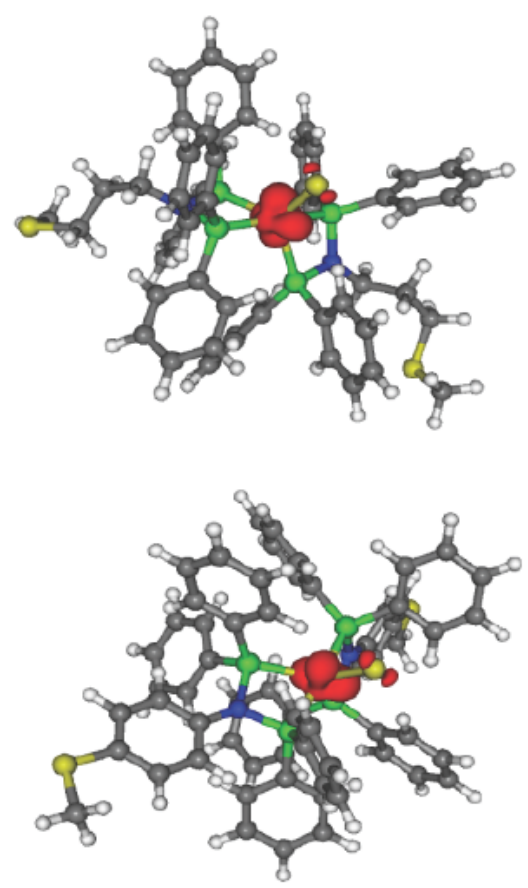

b

Figure 14. a) ADF-view drawing of the Kohn-Sham singly occupied molecular orbitals (SOMOs) of 5 (top) and 7 (bottom). b) Spin density plots for 5 (top) and 7 (bottom).

The ground state geometries for $\mathbf{6}$ and $\mathbf{8}$ were computed using the experimentally determined $S=3 / 2$ ground states. Geometrical parameters calculated for both $\mathbf{6}$ and $\mathbf{8}$ indicated a four-coordinated metal center in a tetrahedral environment, which is in good agreement with the experimental data. However, for complex 6, the calculated distance between $\mathrm{Co} 2$ and the nitrogen atoms was divided by approximately two: the zwitterionic structure induces significant Coulombic attraction. The $\mathrm{Co} 2-\mathrm{S}$ and $\mathrm{Co} 2-\mathrm{Cl}$ distances are slightly overestimated and present the same behavior as described above for $\mathbf{5}$ and 7. For $\mathbf{6}$ and 8 , the metal $3 \mathrm{~d}$-orbitals contribute to the frontier orbitals with a high participation of the $\mathrm{Cl}$ and $\mathrm{S}$ atoms. The three highest occupied molecular orbitals (SOMO) for $\mathbf{6}$ are depicted in Figure S22 (ESI). The EPR spectrum of 8 is dominated by two broad features whereas for 6 only a very broad signal is observed. The spectral features are similar to the EPR spectra of some substituted tetrahedral complexes reported in the literature. ${ }^{43}$ According to calculated 
tetrahedral geometries and EPR data, the Co(II) ions adopt a high spin configuration $S=3 / 2$. The computed $g$ tensors obtained for both compounds are almost axial and reproduce quite satisfactory the EPR data.

For 3 complex, EPR and SQUID data prompted us to assign a low spin state $S=1 / 2$ to Co1 and a high spin state $S=3 / 2$ to Co2. The computed values for 3 reproduced both environments of $\mathrm{Co} 1$ and $\mathrm{Co} 2$ atoms and indicated a reasonable agreement with the X-ray diffraction data. For the Co1-P and Co2-S bond distances, the same overestimation was observed as that mentioned above for mononuclear complexes. Compared to the related mononuclear complexes, the MO diagram for 3 nearly reproduces the addition of the individual MO diagrams. The HOMOs are almost identical in shape with the HOMOs of $\mathbf{5}$ and 6. The computed spin density distribution presented in Figure 15 indicates that the unpaired spin is located on both Co(II) ions. On first inspection, powder EPR spectra and SQUID experiments indicate that both binuclear complexes 3 and $\mathbf{4}$ correspond to the superposition of the fragments developed above and EPR data were simulated with two distinct $g$ tensors corresponding to two paramagnetic centers. Thus, for both dinuclear compounds, we started our computation on the whole molecule by replacing one Co atom with a diamagnetic $\mathrm{Zn}(\mathrm{II})$ center $\left(\mathrm{d}^{10}, S=0\right)$ to reach individual $g$ tensors. The $g$ tensor extracted from EPR simulation for 3 indicates $g_{\mathrm{x}}, g_{\mathrm{y}}>g_{\mathrm{z}}$ for Co1 and supports a low spin ground state identical to $\mathbf{5}$. This is in agreement with the computed $g$ tensor obtained for the low spin Co1 which reproduces quite satisfactory the EPR data. For the high spin Co2, a more important discrepancy was observed between the calculated and the experimental $g$ values.

As no X-ray structure is available for $\mathbf{4}$, two hypotheses could be formulated (Chart 2), one compatible with a zwitterionic form similar to $\mathbf{3}$, the other with a Col center associated with a $\mathrm{CoCl}_{4}$ dianion. For the first hypothesis, we used the data from the crystal structure of the mononuclear Co complex 7 as a fragment to build the dinuclear complex with a similar environment for both Co atoms, as in $\mathbf{3}$ (Figure 1).

As shown in Table S2 (ESI), the calculated geometrical parameters reproduce well the experimental values obtained for 3. The shorter distance calculated between the two metal centers compared to $4(\sim 1.3 \AA)$ is consistent with the flexibility of the alkyl chains in $\mathbf{3}$, which lead to a curved zwitterionic form. As expected, the SOMOs are localized over the cobalt ions with a small participation of the $\mathrm{Cl}, \mathrm{S}$ and $\mathrm{P}$ atoms as observed for 3 (Figure S23 in ESI). The computed spin density distribution for the zwitterionic form (Figure S24 in ESI) indicates that the unpaired spin is localized on both Co atoms. 


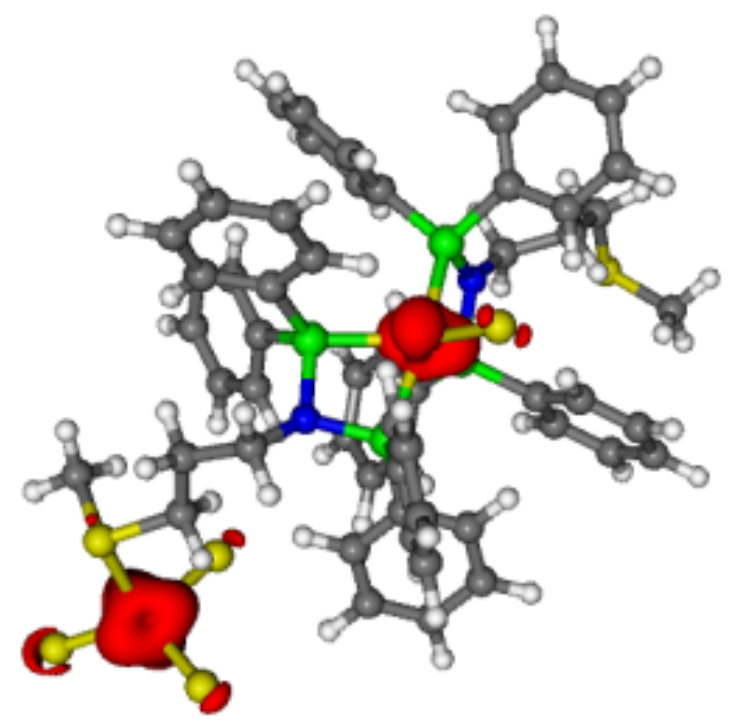

Figure 15. Spin density plots calculated for 3 .

Single point analysis on the optimized structure using the method described above for 3, provides nearly axial $g$ tensors very similar to those for the parent complex 7 for the low spin Co1 and in agreement with the experimental powder EPR spectra. The results for the high spin $\mathrm{Co} 2$ are more nuanced with an important discrepancy.

The second structural hypothesis, thereafter noted 4', was a complex where the Co1 center is associated with a $\mathrm{CoCl}_{4}$ dianion. We only optimized the dication without any counter-ion for the low and high spin states configurations. The calculated geometrical parameters are given in Table S2 (ESI) for the Co1 low spin state. In the absence of the $\mathrm{Cl}$ atom, the tetracoordinated Col could adopt a trigonal pyramidal structure because the steric bulk of the P-phenyl rings prevents a planar structure. The energy difference between the high and low spin states for the anionic form is very small and in favor of the doublet by $0.5 \mathrm{eV}$. We also compared the energies of 4' low spin state and 4, which is lower by $10.6 \mathrm{eV}$. Note that the energy for the anionic form 4' was assessed by the addition of the energies of the two fragments 4' and $\mathrm{CoCl}_{4}$. Such a difference could have been expected as the gas phase approach disfavors charged system: nothing stabilizes the cation-dianion pair. Therefore, the solid state structure of $\mathbf{4}$ is probably best described as a zwitterionic form with a low spin state for the Co1 atom. 


\section{Conclusion}

This work has illustrated the non-trivial coordination chemistry of $\mathrm{Co}$ (II) complexes with two tritopic $P, P, S$ ligands of the $N$-functionalized DPPA-type and provided further examples of the versatile coordination geometries displayed by this metal center. As expected, the different nature of the $N$-substituent in the assembling ligands $\left(\mathrm{Ph}_{2} \mathrm{P}\right)_{2} \mathrm{~N}\left(\mathrm{CH}_{2}\right)_{3} \mathrm{SMe}(\mathbf{1})$ and $\left(\mathrm{Ph}_{2} \mathrm{P}\right)_{2} \mathrm{~N}\left(p-\mathrm{C}_{6} \mathrm{H}_{4}\right) \mathrm{SMe}(2)$, an alkylthioether or an arylthioether group, respectively, has no significant impact on the $P, P$-chelating ability of these diphosphine ligands, which is their main characteristics. However, the higher flexibility of the alkylthioether $N$-substituent and its electron-richer $\mathrm{S}$ atom facilitates coordination of a second metal center. Thus, the dinuclear complex 3 , which was obtained by reaction of ligand $\mathbf{1}$ with $\mathrm{CoCl}_{2}$ in a 1:1 molar ratio, has an original zwitterionic structure consisting of a cationic $\mathrm{CoCl}$ center, bis-chelated by two PNP ligands, and one anionic $\mathrm{CoCl}_{3}$ moiety linked to the $N$-thioether function. The reaction of ligand 2 with $\mathrm{CoCl}_{2}$ in a 1:1 molar ratio led also to a dinuclear complex, 4. To gain a better insight into the structures and properties of these complexes, a retro-synthetic approach was developed, consisting in the synthesis of mononuclear fragments as similar as possible to those constituting the dinuclear complexes, in order to compare their spectroscopic signatures (FT-IR, UV-vis, EPR) with those of the dinuclear complex. First, this approach was successfully applied to $\mathbf{3}$ whose spectroscopic characteristics were analyzed as the superposition of those of the corresponding mononuclear fragments. Magnetic and EPR studies and theoretical calculations were performed in order to gain a more complete understanding of the systems investigated. A combination of solution and solid-state data was used to facilitate comparisons between the molecular fragments and the dinuclear complexes and also with literature data. However, not every technique could be used both in solution and in the solid-state. After validation with 3, this "lego-type" approach was applied to complex $\mathbf{4}$, obtained by reaction of ligand 2 with $\mathrm{CoCl}_{2}$ in a 1:1 molar ratio, for which the structure could not be determined by single crystal X-ray diffraction. We thus synthesized and characterized the complexes $\left[\mathrm{CoCl}(\mathbf{2})_{2}\right] \mathrm{PF}_{6}(\mathbf{7})$ and $\left[\mathrm{H}^{\prime}\right]_{2}\left[\mathrm{CoCl}_{4}\right](\mathbf{8})\left(\mathbf{2}^{\prime}=\mathrm{NH}_{2}\left(p-\mathrm{C}_{6} \mathrm{H}_{4}\right) \mathrm{SMe}\right)$, as models of the elementary bricks constitutive of $\mathbf{4}$. Two possibilities were envisaged for the structure of $\mathbf{4}$, a zwitterionic structure similar to that of complex $\mathbf{3}$, or an ion pair containing a tetrahedral dicationic bis-chelated $\mathrm{Co}$ center associated to a $\mathrm{CoCl}_{4}$ dianion. It was concluded from the spectroscopic data and DFT calculations that the former was more likely. We can anticipate that the approach developed in this work will be useful in other polynuclear systems to evaluate the degree of intramolecular cooperativity between building blocks and in complex 
systems for which structural information cannot always be obtained by single crystal X-ray diffraction.

\section{Experimental Section}

General Procedures. All operations were carried out using standard Schlenk techniques under inert atmosphere. Solvents were purified and dried under nitrogen by conventional methods. IR spectra were recorded in the region $4000-100 \mathrm{~cm}^{-1}$ on a Nicolet 6700 FT-IR spectrometer (ATR mode, SMART ORBIT accessory, Diamond crystal). Elemental analyses were performed by the "Service de microanalyses", Université de Strasbourg and by the “Service Central d'Analyse", USR-59/CNRS, Solaize. Electrospray mass spectra (ESI-MS) were recorded on a microTOF (BrukerDaltonics, Bremen, Germany) instrument using nitrogen as drying agent and nebulising gas and Maldi-TOF analyses were carried out on a BrukerAutiflexII TOF/TOF (BrukerDaltonics, Bremen, Germany), using dithranol (1.8.9 trihydroxyanthracene) as a matrix. All other reagents were used as received from commercial suppliers. Ligands $\mathbf{1}$ and $\mathbf{2}$ were prepared according to literature methods. ${ }^{6 \mathrm{a} 7 \mathrm{~g}}$

\section{Synthesis of the complexes.}

We first describe the complexes containing the ligand $\mathbf{1}$ and then those with ligand 2.

Complex $\left[\mathrm{Co}_{2} \mathrm{Cl}_{4}(\mathbf{1})_{2}\right](\mathbf{3})$

Synthesis resulting from the reaction of $\mathrm{CoCl}_{2}$ with ligand 1

To a suspension of anhydrous $\mathrm{CoCl}_{2}(0.082 \mathrm{~g}, 0.63 \mathrm{mmol})$ in $\mathrm{CH}_{2} \mathrm{Cl}_{2}(10 \mathrm{~mL})$ was added a solution of ligand $1(0.300 \mathrm{~g}, 0.63 \mathrm{mmol})$ in $\mathrm{CH}_{2} \mathrm{Cl}_{2}(20 \mathrm{~mL})$. The solution quickly turned to green and was stirred at room temperature for $12 \mathrm{~h}$. The solution was filtered through a Celite pad to ensure the removing of any unreacted starting material and the solvent was removed under reduced pressure. The resulting dark green solid was washed with diethyl ether and pentane and recrystallized from a mixture of $\mathrm{CH}_{2} \mathrm{Cl}_{2} /$ pentane (1:5), yielding complex $3(0.210$ g, 55\%). Yield based on the crystalline material, however the FTIR spectra of the green powder (precipitated or isolated after drying of the mother liquor) were similar to those of crystals of 3. Red/green crystals suitable for single crystal X-ray diffraction were grown from a mixture of $\mathrm{CH}_{2} \mathrm{Cl}_{2}$ /pentane. Anal. Calcd. for $\mathrm{C}_{56} \mathrm{H}_{58} \mathrm{Cl}_{4} \mathrm{Co}_{2} \mathrm{~N}_{2} \mathrm{P}_{4} \mathrm{~S}_{2}$ (1206.78): C, 55.74; $\mathrm{H}$, 4.84; N, 2.32. Found: C, 55.33; H, 4.83; N, 2.17. FTIR: $v_{\max }\left(\right.$ solid) $/ \mathrm{cm}^{-1} 1770 \mathrm{w}, 1480 \mathrm{w}$, 1433s, 1310w, 1184w, 1091s, 1069sh, 1037sh, 997m, 879m, 734s, 694vs. Far-FTIR: $v_{\max }\left(\right.$ solid) $/ \mathrm{cm}^{-1} 531 \mathrm{~s}, 511 \mathrm{~s}, 502 \mathrm{~s}, 490 \mathrm{~s}, 482 \mathrm{~s}, 319 \mathrm{vs}$. MS (ESI): $\mathrm{m} / z$ (ranked by decreasing intensity) $=1005.1\left[M-\mathrm{H}-\mathrm{CoCl}_{4}\right]^{+}, 1040.1\left[M-\mathrm{CoCl}_{3}\right]^{+}$. 


\section{Synthesis starting from complex 5}

Solid anhydrous $\mathrm{CoCl}_{2}(0.0175 \mathrm{~g}, 0.135 \mathrm{mmol})$ was added to a deep red solution of complex $5(0.080 \mathrm{~g}, 0.067 \mathrm{mmol})$ in $\mathrm{CH}_{2} \mathrm{Cl}_{2}(20 \mathrm{~mL})$. The resulting suspension was stirred overnight, filtered through a Celite pad to remove the " $\mathrm{CoCl}\left(\mathrm{PF}_{6}\right)$ " formed and concentrated to a quarter of its original volume under reduced pressure. Addition of pentane $(50 \mathrm{~mL})$ led to the precipitation of a green powder, isolated by filtration, dried under reduced pressure and identified as complex 3 by FT-IR and EA ( $0.043 \mathrm{~g}$, 53\% based on complex 5). FT-IR data are superimposable to those described above and EA found for this sample: $\mathrm{C}, 55.46 ; \mathrm{H}, 4.77 ; \mathrm{N}$, 2.29 (Calcd. C, 55.74; H, 4.84; N, 2.32).

\section{Complex $\left[\mathrm{CoCl}(\mathbf{1})_{2}\right] \mathrm{PF}_{6}(\mathbf{5})$}

A solution of ligand $1(0.500 \mathrm{~g}, 1.06 \mathrm{mmol})$ in $\mathrm{CH}_{2} \mathrm{Cl}_{2}(20 \mathrm{~mL})$ was added to a mixture of anhydrous $\mathrm{CoCl}_{2}(0.069 \mathrm{~g}, 0.53 \mathrm{mmol})$ and $\mathrm{KPF}_{6}(0.097 \mathrm{~g}, 0.53 \mathrm{mmol})$ in $\mathrm{CH}_{2} \mathrm{Cl}_{2}(10 \mathrm{~mL})$. The solution turned to brown and was stirred for $12 \mathrm{~h}$. The solution was filtered through a Celite pad to ensure the removing of any unreacted starting material and the solvent was removed under reduced pressure. The resulting red/brown solid was washed with diethyl ether and pentane and recrystallized from a mixture of $\mathrm{CH}_{2} \mathrm{Cl}_{2} /$ pentane, affording red crystals of complex 5 (0.590 g, 94\%). Anal. Calcd. for $\mathrm{C}_{56} \mathrm{H}_{58} \mathrm{ClCoF}_{6} \mathrm{~N}_{2} \mathrm{P}_{5} \mathrm{~S}_{2} \cdot 3 \mathrm{CH}_{2} \mathrm{Cl}_{2}$ (1441.25): $\mathrm{C}$, 49.17; H, 4.48; N, 1.94. Found: C, 48.78; H, 4.47; N, 1.87. FTIR: $v_{\max }\left(\right.$ solid)/ $/ \mathrm{cm}^{-1} 1434 \mathrm{~m}$, $1312 \mathrm{w}, 1187 \mathrm{w}, 1091 \mathrm{~s}, 999 \mathrm{w}, 834 \mathrm{vs}, 734 \mathrm{~s}, 693 \mathrm{~s}$. Far-FTIR: $v_{\max }\left(\right.$ solid)/cm ${ }^{-1} 556 \mathrm{vs}, 530 \mathrm{vs}$, 513vs, 501vs, 490vs, 418m. MS (ESI): $m / z 1040.2\left[M-\mathrm{PF}_{6}\right]^{+}$.

\section{Complex $\left[\mathrm{CoCl}_{3}\left(\mathrm{H1} \mathbf{1}^{\prime}\right)\right](\mathbf{6})\left(\mathbf{1}^{\prime}=\mathrm{NH}_{2}\left(\mathrm{CH}_{2}\right)_{3} \mathrm{SMe}\right)$}

An aqueous $\mathrm{HCl}$ solution $\left(0.40 \mathrm{~mL}\right.$ of $37 \% \mathrm{HCl}$ in $\mathrm{H}_{2} \mathrm{O}$, corresponding to $4.75 \mathrm{mmol}$ of $\mathrm{HCl}$ ) was added to a solution of 3-(methylthio)propylamine $(0.53 \mathrm{~mL}, 0.500 \mathrm{~g}, 4.75 \mathrm{mmol})$ in $\mathrm{CH}_{2} \mathrm{Cl}_{2}$. A white precipitate was instantaneously formed. Anhydrous $\mathrm{CoCl}_{2}(0.617 \mathrm{~g}, 4.75$ mmol) was then added to the suspension, which turned blue, and the mixture was stirred for 2 $\mathrm{h}$. The volatiles were then removed under reduced pressure and the solid was washed with diethyl ether $(2 \times 20 \mathrm{~mL})$. Complex 6 was isolated as a blue powder $(1.11 \mathrm{~g}, 86 \%)$. Anal. Calcd. for $\mathrm{C}_{4} \mathrm{H}_{12} \mathrm{Cl}_{3} \mathrm{CoNS}$ (271.50): C, 17.70; H, 4.45; N, 5.16. Found: C, 17.66; H, 4.75; N, 5.29. FTIR: $v_{\max }\left(\right.$ solid) $/ \mathrm{cm}^{-1} 3102 \mathrm{~s}, 2941 \mathrm{~m}, 1572 \mathrm{~m}, 1486 \mathrm{~s}, 1443 \mathrm{~m}, 1244 \mathrm{w}, 1217 \mathrm{w}, 1114 \mathrm{w}$, 1097m, 1040w, 978m, 932m, 827w, 773w. Far-FTIR: $v_{\max }\left(\right.$ solid)/(cm ${ }^{-1} 489 \mathrm{w}, 459 \mathrm{w}, 433 \mathrm{w}$, 289vs. MS (ESI): $m / z 234.9$ [M-Cl] $]^{+}$ 


\section{Complex $\left[\mathrm{CoCl}_{2}(\mathbf{2})\right]_{2}(\mathbf{4})$.}

The same procedure as for complex 3 was used with anhydrous $\mathrm{CoCl}_{2}(0.051 \mathrm{~g}, 0.39 \mathrm{mmol})$ and ligand $2(0.200 \mathrm{~g}, 0.39 \mathrm{mmol})$ and afforded complex 4 as green crystalline solid $(0.208 \mathrm{~g}$, 83\%). Anal. Calcd. for $\mathrm{C}_{62} \mathrm{H}_{54} \mathrm{Cl}_{4} \mathrm{Co}_{2} \mathrm{~N}_{2} \mathrm{P}_{4} \mathrm{~S}_{2}$ (1274.81): C, 58.41; H, 4.27; N, 2.20. Found: C,

58.77; H, 4.54; N, 2.35. FTIR: $v_{\max }\left(\right.$ solid)/ $\mathrm{cm}^{-1} 1586 \mathrm{w}, 1491 \mathrm{~m}, 1433 \mathrm{~s}, 1299 \mathrm{w}, 1271 \mathrm{w}, 1217 \mathrm{~m}$, 1158w, 1093s, 1026w, 1010w, 998w, 934m, 894s, 811w, 736s, 691vs. Far-FTIR: $\nu_{\max }\left(\right.$ solid) $/ \mathrm{cm}^{-1} 554 \mathrm{~m}, 526 \mathrm{~s}, 495 \mathrm{~s}, 423 \mathrm{w}, 295 \mathrm{~s}$. MS (ESI): $\mathrm{m} / z$ (ranked by decreasing intensity $)=1073.1\left[M-\mathrm{H}-\mathrm{CoCl}_{4}\right]^{+}, 1108.1\left[M-\mathrm{CoCl}_{3}\right]^{+}$.

\section{Synthesis starting from complex 7}

The same procedure as for complex 3 was followed, with $\mathrm{CoCl}_{2}(0.0186 \mathrm{~g}, 0.143 \mathrm{mmol})$, complex 7 (0.090 g, $0.072 \mathrm{mmol})$ in $\mathrm{CH}_{2} \mathrm{Cl}_{2}(20 \mathrm{~mL})$, affording complex $4(0.057 \mathrm{~g}, 62 \%)$. FT-IR data are superimposable to those described above and EA found for this sample: C, 58.38; H, 4.49; N, 2.30 (Calcd. C, 58.41; H, 4.27; N, 2.20).

\section{Complex $\left[\mathrm{CoCl}(2)_{2}\right] \mathrm{PF}_{6}(7)$}

The same procedure as for complex 5 was used with anhydrous $\mathrm{CoCl}_{2}(0.064 \mathrm{~g}, 0.49 \mathrm{mmol})$, $\mathrm{KPF}_{6}(0.091 \mathrm{~g}, 0.49 \mathrm{mmol})$ and ligand $2(0.500 \mathrm{~g}, 0.99 \mathrm{mmol})$ and afforded green crystals of complex 7 (0.580 g, 94\%). Anal. Calcd. for $\mathrm{C}_{62} \mathrm{H}_{54} \mathrm{ClCoF}_{6} \mathrm{~N}_{2} \mathrm{P}_{5} \mathrm{~S}_{2} \cdot \mathrm{H}_{2} \mathrm{O}$ (1272.50): C, 58.52; H, 4.44; N, 2.20. Found: C, 58.60; H, 4.43; N, 1.87. FTIR: $v_{\max }\left(\right.$ solid) $/ \mathrm{cm}^{-1} 1490 \mathrm{~m}, 1434 \mathrm{~m}$, $1217 \mathrm{~m}, 1094 \mathrm{~m}, 937 \mathrm{~m}, 898 \mathrm{~m}, 836 \mathrm{vs}, 736 \mathrm{~m}, 694 \mathrm{~s}$. Far-FTIR: $v_{\max }($ solid $) / \mathrm{cm}^{-1} 556 \mathrm{~s}, 526 \mathrm{vs}$, 514sh, 492vs, 443m. MS (ESI): $m / z$ 1108.2 [M-PF $]^{+}$.

\section{Complex $\left[\mathrm{H}^{\prime}\right]_{2}\left[\mathrm{CoCl}_{4}\right](\mathbf{8})\left(\mathbf{2}^{\prime}=\mathrm{NH}_{2}\left(p-\mathrm{C}_{6} \mathrm{H}_{4}\right) \mathrm{SMe}\right)$}

The same procedure as for complex 6 was used with anhydrous $\mathrm{CoCl}_{2}(0.466 \mathrm{~g}, 3.59 \mathrm{mmol})$, aqueous $\mathrm{HCl}$ solution $\left(0.29 \mathrm{~mL}\right.$ of $37 \% \mathrm{HCl}$ in $\mathrm{H}_{2} \mathrm{O}$, corresponding to $3.59 \mathrm{mmol}$ of $\left.\mathrm{HCl}\right)$ and 4-(methylthio)aniline $(0.45 \mathrm{~mL}, 0.500 \mathrm{~g}, 3.59 \mathrm{mmol})$. Unreacted $\mathrm{CoCl}_{2}$ was removed by water washing, before additional $\mathrm{Et}_{2} \mathrm{O}$ washing and complex 8 was isolated as a blue powder $(0.760$ g, $44 \%$, based on $\mathrm{CoCl}_{2}$ used). Anal. Calcd. for $\mathrm{C}_{14} \mathrm{H}_{20} \mathrm{Cl}_{4} \mathrm{CoN}_{2} \mathrm{~S}_{2} \cdot 4 \mathrm{H}_{2} \mathrm{O}$ (553.26): C, 30.39; $\mathrm{H}$, 5.10; N, 5.06. Found: C, 30.26; H, 5.17; N, 4.92. FTIR: $v_{\max }\left(\right.$ solid) $/ \mathrm{cm}^{-1} 3444 \mathrm{~m}, 3372 \mathrm{~m}$, 2989w, 2947w, 1611m, 1453s, 1402m, 1309w, 1184s, 1082w, 1034m, 1006s, 794s, 710w. Far-FTIR: $v_{\max }\left(\right.$ solid) $/ \mathrm{cm}^{-1} 322 \mathrm{~m}, 294 \mathrm{~s}, 272 \mathrm{~s}, 226 \mathrm{~m}, 168 \mathrm{~m}, 125 \mathrm{vs}$. MS (ESI): $\mathrm{m} / \mathrm{z} 140.1$ $\left[\mathrm{CH}_{3} \mathrm{~S}\left(\mathrm{C}_{6} \mathrm{H}_{4}\right) \mathrm{NH}_{3}\right]^{+}$. 
$X$-ray data collection, structure solution and refinement for all compounds. Suitable crystals for the X-ray analysis of all compounds were obtained as described above. The intensity data were collected on a Kappa CCD diffractometer ${ }^{44}$ (graphite monochromated $\mathrm{MoK}_{\alpha}$ radiation, $\lambda=0.71073 \AA$ ) at $173(2) \mathrm{K}$. Crystallographic and experimental details for the structures are summarized in Table S1 (ESI). The structures were solved by direct methods (SHELXS-97) and refined by full-matrix least-squares procedures (based on $F^{2}$, SHELXL-97) ${ }^{45}$ with anisotropic thermal parameters for all the non-hydrogen atoms. The hydrogen atoms were introduced into the geometrically calculated positions (SHELXS-97 procedures) and refined riding on the corresponding parent atoms. For some compounds a MULTISCAN correction was applied. ${ }^{46}$

Magnetic measurements. Measurements were performed on microcrystalline samples enclosed in $30 \mu \mathrm{m}$ polyethylene bags. Weights were accurately determined with a Mettler Toledo MX5 microbalance. The bags diamagnetic contribution was subtracted from the measured magnetic moments with a diamagnetic correction combined to a small Curie tail determined previously on a massive sample. Measurements were performed on Quantum Design MPMS-5XL with a dc probe and MPMS-7 with a RSO probe SQUID magnetometers, data were corrected when necessary with locally developed procedures using multipole fitting. ${ }^{47}$ Sample diamagnetic contributions were approximated using Pascal constants. Magnetic simulations were calculated with a locally modified version of the Magpack software. $^{48}$

EPR measurements. X-band (Larmor frequency $~ 9.3 \mathrm{GHz}$ ) EPR spectra were recorded with a continuous-wave EMXplus spectrometer (BrukerBiospin GmbH, Germany) equipped with a high sensitivity resonator (4119HS-W1, Bruker). The spectrometer was tuned so as settings (modulation coils, incident microwave power) did not distort the EPR signal. Measurements were carried out on powdered samples held at 4-5 K. Simulations were completed with the EasySpin free software (http://www.easyspin.org).

Computational details. Ground state electronic structures have been calculated by DFT methods using Amsterdam Density Functional (ADF2010.02). ${ }^{49}$ Geometry optimization was based on the hybrid B3LYP exchange-correlation functional. ${ }^{50,51} \mathrm{~A}$ standard triple- $\zeta$ slater basis set was used for all atoms. All calculations were performed within the unrestricted formalism. Relativistic effects were not included. The ORCA package ${ }^{52}$ was used to calculate 
EPR properties through a single point on ADF optimized geometries. B3LYP exchangecorrelation functional was applied with TZVP basis $^{53}$ for the metal centers and the remaining atoms. Representations of the molecular structures and orbitals were made using ADFview v06. The obtained wavefunctions were analyzed with the DGRID package to compute maps of spin density. ${ }^{54}$

\section{Supporting Information}

Supporting Information. X-ray data collection and structure refinement for all compounds. CCDC numbers 1440248-1440252 (3.2( $\left(\mathrm{CH}_{2} \mathrm{Cl}_{2}\right), \mathbf{4} \cdot \mathrm{CH}_{2} \mathrm{Cl}_{2}, \mathbf{5}, 7$ and 8) and 1451018$1451019\left(\mathbf{9}\right.$ and $\mathbf{1 0} \cdot \mathrm{CH}_{2} \mathrm{Cl}_{2}$ ). Far-FT-IR spectra and UV-vis spectra of compounds 3, 4, 5, $\mathbf{6}$, 7 and 8. Molar susceptibility plots $v s$. $T$ and isothermal magnetization plots for compounds $\mathbf{3}$, 4, 5, 6, 7 and 8. Representation of the magnetic pair compound 5. Representation of the magnetic layers in compound $\mathbf{8}$. Relevant computed geometrical parameters for complexes 38. ADF-view drawings of the Kohn-Sham highest occupied molecular orbitals (SOMOs) of complexes 6 and 4. Spin density plots calculated for 4. Principal $g$-values for complexes 5-8 and $\mathrm{Zn}(\mathrm{II})$ model complexes of $\mathbf{3}$ and $\mathbf{4}$.

The Supporting Information is available free of charge on the ACS Publications website at DOI:

\section{Acknowledgements}

We are grateful to the CNRS, the Ministère de la Recherche (Paris), the french EPR Federation of Research (REseau NAtional de Rpe interDisciplinaire, RENARD, Fédération IR-RPE CNRS 3443), the DFH/UFA (International Research Training Group 532-GRK532, $\mathrm{PhD}$ grant to C.F.), and the Fundação para a Ciência e Tecnologia (FCT) (fellowships SFRH/BPD/73253/2010 to C.F. and SFRH/BPD/44262/2008 to V.R.) for financial and scientific supports. We thank Dr. L. Karmazin and Miss C. Bailly (Service de radiocristallographie, Institut de Chimie, Unistra) and Dr. R. Pattacini for the X-ray diffraction studies and Dr. D. Specklin for the graphical Figures 1-5. We thank the highperformance computing center of the University of Strasbourg for computation facilities. 


\section{References}

(1) For selected reviews see e.g.: (a) Hierso, J.-C.; Amardeil, R.; Bentabet, E.; Broussier, R.; Gautheron, B.; Meunier, P.; Kalck, P. Coord. Chem. Rev. 2003, 236, 143-206; (b) T. Appleby, J. D. Woollins, Coord. Chem. Rev. 2002, 235, 121-140; (c) P. Bhattacharyya, J. D. Woollins, Polyhedron, 1995, 14, 3367-3388. Other specific examples are cited along the manuscript.

(2) (a) Rosa, V.; Fliedel, C.; Ghisolfi, A.; Pattacini, R.; Avilés, T.; Braunstein, P. Dalton Trans. 2013, 42, 12109-12119; (b) Fliedel, C.; Pattacini, R.; Braunstein, P. J. Clust. Sci. 2010, 21, 397-415; (c) Ganesamoorthy, C.; Balakrishna, M. S.; Mague, J. T. Inorg. Chem. 2009, 48, 3768-3782; (d) Rodriguez-Zubiri, M.; Gallo, V.; Rosé, J.; Welter, R.; Braunstein, P. Chem. Commun. 2008, 64-66; (e) Gallo, V.; Mastrorilli, P.; Nobile, C. F.; Braunstein, P.; Englert, U. Dalton Trans. 2006, 2342-2349.

(3) (a) Lin, B.; Liu, Z.; Liu, M.; Pan, C.; Ding, J.; Wu, H.; Cheng, J. Catal. Commun. 2007, 8, 2150-2152; (b) Posset, T.; Rominger, F.; Blümel, J. Chem. Mater. 2005, 17, 586-595; (c) Schweyer-Tihay, F.; Braunstein, P.; Estournès, C.; Guille, J. L.; Lebeau, B.; Paillaud, J.-L.; Richard-Plouet, M.; Rosé, J. Chem. Mater. 2003, 15, 57-62; (d) Braunstein, P.; Kormann, H.P.; Meyer-Zaika, W.; Pugin, R.; Schmid, G. Chem. Eur. J. 2000, 6, 4637-4646.

(4) Fliedel, C.; Faramarzi, V.; Rosa, V.; Doudin, B.; Braunstein, P. Chem. Eur. J. 2014, 20, 1263-1266.

(5) For recent examples see e.g.: (a) Aydemir, M.; Baysal, A.; Sahin, E.; Gümgüm, B.; Özkar, S. Inorg. Chim. Acta, 2011, 378, 10-18; (b) Ganesamoorthy, C.; Balakrishna, M. S.; Mague, J. T. J. Organomet. Chem. 2009, 694, 3390-3394; (c) Ganesamoorthy, C.; Balakrishna, M. S.; Mague, J. T.; Tuononen, H. M. Inorg. Chem. 2008, 47, 7035-7047; (d) R. Paolillo, V. Gallo, P. Mastrorilli, C. F. Nobile, J. Rosé, P. Braunstein, Organometallics 2008, 27, 741-746; (e) Gümgüm, B.; Biricik, N.; Durap, F.; Özdemir, I.; Gürbüz, N.; Ang, W. H.; Dyson, P. J. Appl. Organomet. Chem. 2007, 21, 711-715; (f) Mandal, S. K.; Gowda, G. A. N.; Krishnamurthy, S. S.; Zheng, C.; Li, S.; Hosmane N. S. J. Organomet. Chem. 2003, 676, 22-37.

(6) For examples of Ni-based catalysts, see e.g.: (a) Ghisolfi, A.; Fliedel, C.; Rosa, V.; Yu. Monakhov, K.; Braunstein, P. Organometallics 2014, 33, 2523-2534; (b) Schultz, M.; Eisenträger, F.; Regius, C.; Rominger, F.; Hanno-Igels, P.; Jakob, P.; Gruber, I.; Hofmann, P. Organometallics 2012, 31, 207-224; (c) Song, K.; Gao, H.; Liu, F.; Pan, J.; Guo, L.; Zai, S.; Wu, Q. Eur. J. Inorg. Chem. 2009, 3016-3024; (d) Lavanant, L.; Rodrigues, A.-S.; Kirillov, E.; Carpentier, J.-F.; Jordan, R. F. Organometallics, 2008, 27, 2107-2117; (e) Dennett, J. N. 
L.; Gillon, A. L.; Heslop, K.; Hyett, D. J.; Fleming, J. S.; Lloyd-Jones, C. E.; Orpen, A. G.; Pringle, P. G.; Wass, D. F.; Scutt, J. N.; Weatherhead, R. H. Organometallics 2004, 23, $6077-$ 6079; (f) Cooley, N. A.; Green, S. M.; Wass, D. F.; Heslop, K.; Orpen, A. G.; Pringle, P. G. Organometallics 2001, 20, 4769-4771; (g) Wass, D. F. (BP Chemicals Ltd), WO01/10876; (h) Hofmann, P.; Perez-Moya, L. A.; Steigelmann, O.; Riede, J. Organometallics 1992, 11, 1167-1176; (i) Hofmann, P.; Perez-Moya, L. A.; Krause, M. E.; Kumberger, O.; Müller, G. Z. Naturforsch. 1990, 45b, 897-908.

(7) For general recent reviews on Cr-based catalysts, see e.g.: (a) Dagorne, S.; Fliedel, C. Top. Organomet. Chem. 2013, 41, 125-171; (b) McGuinness, D. S. Chem. Rev. 2011, 111, 23212341; (c) Agapie, T. Coord. Chem. Rev. 2011, 255, 861-880; (d) van Leeuwen, P. W. N. M.; Clément, N. D.; Tschan, M. J. L. Coord. Chem. Rev. 2011, 255, 1499-1517.

For other examples of Cr-based catalysts, see e.g.: (e) Reddy Aluri, B.; Peulecke, N.; Peitz, S.; Spannenberg, A.; Müller, B. H.; Schulz, S.; Drexler, H.-J.; Heller, D.; Al-Hazmi, M. H.; Mosa, F. M.; Wöhl, A.; Müller, W.; Rosenthal, U. Dalton Trans. 2010, 39, 7911-7920 (Cr and Ni complexes); (f) Zhang, J.; Braunstein, P.; Hor, T. S. A. Organometallics 2008, 27, 4277-4279; (g) Weng, Z.; Shihui, T.; Hor, T. S. A. Dalton Trans. 2007, 3493-3498.

(8) Lippard, S. J.; Berg, J. M. Principles of Bioinorganic Chemistry; University Science Books: Mill Valley, CA, 1994; Chapter 12.

(9) (a) Raphael, A. L.; Gray, H. B. J. Am. Chem. Soc. 1991, 113, 1038-1040; (b) Geno, M. K.; Halpern, J. J. Am. Chem. Soc. 1987, 109, 1238-1240; (c) Perutz, M. F.; Fermi, G.; Luisi, B.; Shaanan, B.; Liddington, R. C. Acc. Chem. Res. 1987, 20, 309-321; (d) Halpern, J. Science 1985, 227, 869-875; (e) Garret, T. P. J.; Glingeleffer, D. J.; Guss, J. M.; Rogers, S. J.; Freeman, H. C. J. Biol. Chem. 1984, 259, 2822-2825.

(10) Ghisolfi, A.; Condello, F.; Fliedel, C.; Rosa, V.; Braunstein, P. Organometallics 2015, $34,2255-2260$.

(11) Fliedel, C.; Rosa, V.; Falceto, A.; Rosa, P.; Alvarez, S.; Braunstein P. Inorg. Chem. 2015, $54,6547-6559$

(12) For recent examples see e.g.: (a) Ok, F.; Aydemir, M.; Durap, F., Appl. Organomet. Chem. 2014, 28, 38-43; (b) Naik, S.; Mague, J. T.; Balakrishna, M. S., Inorg. Chim. Acta 2013, 407, 139-144; (c) Sarcher, C.; Lebedkin, S.; Kappes, M. M.; Fuhr, O.; Roesky, P. W., J. Organomet. Chem. 2013, 751, 343-350; (d) Aydemir, M.; Meric, N.; Kayan, C.; Ok, F.; Baysal, A., Inorg. Chim. Acta 2013, 398, 1-10.

(13) (a) Catalysis without Precious Metals, R. M. Bullock (Ed.), Wiley-VCH, Weinheim 
(2010); (b) Biochemistry and Inorganic Chemistry: Influence on Structure and Reactivity, M. Swart and M. Costas (Eds), John Wiley \& Sons, Ltd, Oxford, UK (2015); (c) Poli, R.; Allan, L. E. N.; Shaver, M. P. Prog. Polym. Sci. 2014, 39, 1827-1845; (d) Pedersen, K. S.; Bendix, J.; Clérac, R. Chem. Commun. 2014, 50, 4396-4415; (e) Grohmann, A. Dalton Trans. 2010, 39, 1432-1440; (f) Debuigne, A.; Poli, R.; Jérôme, C.; Jérôme, R.; Detrembleur, C. Prog. Polym. Sci. 2009, 34, 211-239.

(14) (a) Ghisolfi, A.; Monakhov, K. Yu.; Pattacini, R.; Braunstein, P.; López, X.; de Graaf, C.; Speldrich, M.; van Leusen, J.; Schilder, H.; Kögerler, P. Dalton Trans. 2014, 43, 78477859; (b) Pattacini, R.; Teo, P.; Zhang, J.; Lan, Y.; Powell, A. K.; Nehrkorn, J.; Waldmann, O.; Hor, T. S. A.; Braunstein P. Dalton Trans. 2011, 40, 10526-10534.

(15) (a) Naktode, K.; Kottalanka, R. K.; Panda, T. K. J. Coord. Chem. 2014, 67, 3042-3053; (b) Zhang, Z.-Z.; Yu, A.; Xi, H.-P.; Wang, R.-J.; Wang, H.-G. J. Organomet. Chem. 1994, 470, 223-229; (c) Werner, H.; Lippert, F.; Peters, K.; von Schnering, H. G. Chem. Ber. 1992, $125,347-352$.

(16) (a) Soobramoney, L.; Bala, M. D.; Friedrich, H. B. Dalton Trans. 2014, 43, 1596815978; (b) Slepukhin, P. A.; Kim, D. M.; Charushin, V. N. Koord. Khim. (Russ.) (Coord. Chem.) 2010, 36, 615-617; (c) Baumann, G.; Marzilli, L. G. ; Nix, C. L.; Rubin B. Inorg. Chim. Acta 1983, 77, L35-L37.

(17) Alvarez, S.; Llunell, M. Dalton Trans. 2000, 3288. See also: Alvarez, S. Chem. Rev. 2015, 115, 13447-13483, and references cited therein.

(18) Ghisolfi, A.; Fliedel, C.; Rosa, V.; Pattacini, R.; Thibon, A.; Monakhov, K. Yu.; Braunstein, P. Chem. Asian J. 2013, 8, 1795-1805.

(19) Cotton, F. A.; Wilkinson, G; Murillo, C.; Bochmann, A. M. Advanced Inorganic Chemistry, $6^{\text {th }}$ ed.; John Wiley \& Sons: New York, 1999; pp 817-822.

(20) Li, J.; Merkel, S.; Henn, J.; Meindl, K.; Döring, A.; Roesky, H. W.; Ghadwal, R. S.; Stalke, D. Inorg. Chem. 2010, 49, 775-777

(21) Mondal, K. C.; Samuel, P. P.; Roesky, H. W.; Carl, E.; Herbst-Irmer, R.; Stalke, D.; Schwederski, B.; Kaim, W.; Ungur, L.; Chibotaru, L. F.; Hermann, M.; Frenking, G. J. Am. Chem. Soc. 2014, 136, 1770-1773.

(22) (a) Farona, M. F.; White, J. F. Inorg. Chem. 1971, 10, 1080-1081; (b) Dyer, G.; Meek, D. W. J. Am. Chem. Soc. 1967, 89, 3983-3987.

(23) Nishida, Y.; Kida, S. Bull. Chem. Soc. JPN 1975, 48, 1045-1046. 
(24) Pietrzyk, P.; Srebro, M.; Radoń, M.; Sojka, Z.; Michalak, A. J. Phys. Chem. A 2011, 115, 2316-2324.

(25) Marts, A. R.; Greer, S. M.; Whitehead, D. R.; Woodruff, T. M.; Breece, R. M.; Shim, S.W.; Oseback, S. N.; Papish, E. T.; Jacobsen, F. E.; Cohen, S. M.; Tierney D. L. Appl. Magn. Reson. 2011, 40, 501-511.

(26) Bennett, B. Curr. Topics Biophys. 2002, 26, 49-57.

(27) Myers, W. K.; Duesler, E. N.; Tierney, D. L. Inorg. Chem. 2008, 47, 6701-6710.

(28) Jacobsen, F. E.; Breece, R. M.; Myers, W. K.; Tierney, D. L.; Cohen, S. M. Inorg. Chem. 2006, $45,7306-7315$.

(29) Nishida, Y.; Shimohori, H. Bull. Chem. Soc. Jpn., 1973, 46, 2406-2410.

(30) Figgis, B. N.; Hitchman, M. A. Ligand Field Theory and Its Applications, Wiley_VCH. New-York (USA), 2000, pp 228-263.

(31) Banci, L.; Bencini, A.; Benelli, C.; Gatteschi, D.; Zanchini, C. Struct. Bonding 1982, 52, 37-86.

(32) Cossee, P.; van Arkel, A. E. J. Phys. Chem. Solids 1960, 15, 1-6.

(33) W. DeW. Horrocks Jr. D. A. Burlone, J. Am. Chem. Soc. 1976, 98, 6512-6516.

(34) Dyrek, K.; Dyrek, M.; Wesełucha-Birczyńska, A. Polyhedron 1985, 4, 169-172.

(35) Qu, T.; Kuang, X.-Y.; Li, Y.-F.; Chai, R.-P. Chem. Phys. Lett. 2011, 504, 170-174.

( 36 ) Boča, R. Theoretical foundations of Molecular Magnetism. Elsevier, Lausanne (Switzerland), 1999, chapters 5 and 9.

(37) Hamiltonian $\widehat{H}=\beta g \sum \hat{S} \cdot \widehat{H}-2 J \hat{S}_{1} \hat{S}_{2}+\sum D \hat{S}_{z}^{2}+E\left(\hat{S}_{x}^{2}-\hat{S}_{y}^{2}\right)$

(38) $\theta=\frac{z 2 J S(S+1)}{3 k}$

(39) It must be noted that an uncorrected ferromagnetic impurity would give a similar contribution than a very high TIP, but magnetization measurements at $100 \mathrm{~K}$ did not evidence such an impurity.

(40) Though no maximum is observed on the susceptibility plot, a similar behavior was observed for the isothermal magnetization of a 2D Heisenberg honeycomb lattice model, see Curély, J.; Lloret, F.; Julve, M. Phys. Rev. B 1998, 58, 11465-11483.

(41) Only visual agreement was sought for. Since parameters are likely to be heavily correlated, the parameters are certainly neither unique nor optimal.

(42) (a) Drago, R. S.; Stahlbush, J. R.; Kitko, D. J.; John, B. J. Am. Chem. Soc. 1980, 102, 1884-1889; (b) Stelzer, O.; Sheldrick, W. S.; Subramanian, J. J. Chem. Soc., Dalton Trans. 1977, 966-970. 
(43) (a) Krzystek, J.; Ozarowski, A.; Zvyagin, S. A; Telser, J. Inorg. Chem. 2012, 51, 49544964; (b) Krzystek, J.; Zvyagin, S. A; Ozarowski, A.; Fiedler, A. T.; Brunold, T. C.; Telser, J. J. Am. Chem. Soc. 2004, 126, 2148-2155; (c) Romerosa, A.; Saraiba-Bello, C.; Serrano-Ruiz, M.; Caneschi, A.; Mckee, V.; Peruzzini, M.; Zanobini, F. Dalton Trans. 2003, 3233-3239; (d) Makinen, M. W.; Kuo, L. C.; Yim, M. B.; Wells, G. B.; Fukuyama, J. M.; Kim, J. E.; J. Am. Chem. Soc. 1985, 107, 5245-5255.

(44) Bruker-Nonius, Kappa CCD Reference Manual,Nonius BV, The Netherlands, 1998.

(45) Sheldrick, G. M. Acta Cryst. 2008, A64, 112-122.

(46) (a) Spek, L. J. Appl. Cryst. 2003, 36, 7-13; (b) Blessing, B. Acta Cryst., 1995, A51, 33-38.

(47) Palamarciuc, T.; Oberg, J. C.; El Hallak, F.; Hirjibehedin, C. F.; Serri, M.; Heutz, S.; Létard, J.-F.; Rosa, P., J. Mater. Chem. 2012, 22, 9690-9695.

(48) Borrás-Almenar, J. J.; Clemente-Juan, J. M.; Coronado, E.; Tsukerblat, B. S. Inorg. Chem. 1999, 38, 6081-6088 and J. Comput. Chem. 2001, 22, 985-991.

(49) ADF2010.02 Theoretical Chemistry; Vrije Universiteit: Amsterdam, The Netherlands, SCM.

(50) Becke, A. D. J. Chem. Phys. 1993, 98, 5648-5652.

(51) Lee, C.; Yang, W.; Parr, R. G. Phys. Rev. B 1988, 37, 785-789.

(52) (a) Neese, F. ORCA An Ab Initio, DFT and Semiempirical Electronic Structure Package, version 2.9.1; Universität Bonn: Bonn, Germany. (b) Neese, F. J. Chem. Phys. 2007, 127, 164112.

(53) (a) Schäfer, A.; Hom, H.; Ahlrichs, R.; J. Chem. Phys., 1992, 97, 2571-2577; (b) Schäfer, A.; Huber, C.; Ahlrichs, R. J. Chem. Phys. 1994, 100, 5829-5835.

(54) M. Kohout, DGrid, version 4.6, Radebeul, 2011. 


\section{For Table of Contents Only}

Assembling complexes... Thioether-functionalized DPPA-type short-bite assembling ligands $\left(\mathrm{Ph}_{2} \mathrm{P}\right)_{2} \mathrm{~N}\left(\mathrm{CH}_{2}\right)_{3} \mathrm{SMe}$ (1) and $\left(\mathrm{Ph}_{2} \mathrm{P}\right)_{2} \mathrm{~N}\left(p-\mathrm{C}_{6} \mathrm{H}_{4}\right) \mathrm{SMe}$ (2) react with $\mathrm{CoCl}_{2}$ to afford the dinuclear complexes $\left[\mathrm{CoCl}_{2}(\mathbf{1} \text { or } \mathbf{2})\right]_{2}$ (3 or 4). Relevant mononuclear complexes were prepared to study the relationship of their FT-IR, UV-vis, EPR and magnetic properties with those of the dinuclear complexes. From these comparisons and DFT calculations, it was concluded that $\mathbf{4}$ is best described as a zwitterion, like $\mathbf{3}$, with a low spin state Co1 atom.

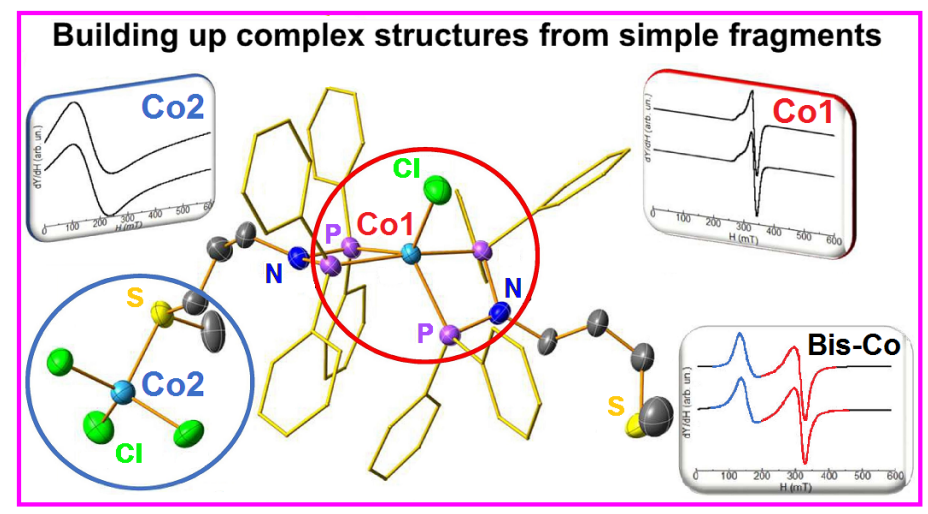

